\title{
Just How Good are the Top Three Journals in Finance? An Assessment Based on Quantity and Quality Citations*
}

\author{
Chia-Lin Chang \\ Department of Applied Economics \\ Department of Finance \\ National Chung Hsing University \\ Taiwan
}

Michael McAleer

Department of Quantitative Finance

National Tsing Hua University

Taiwan

and

Econometric Institute

Erasmus School of Economics

Erasmus University Rotterdam

and

Tinbergen Institute

The Netherlands

and

Department of Quantitative Economics

Complutense University of Madrid

May 2014

* For financial support, the first author wishes to thank the National Science Council, Taiwan, and the second author wishes to acknowledge the Australian Research Council and the National Science Council, Taiwan. The paper was prepared for presentation at the Annual Meeting of the Taiwan Finance Association, May 2014, Hsinchu, Taiwan. 


\begin{abstract}
The paper is concerned with ranking academic journal quality and research impact in Finance, based on the widely-used Thomson Reuters ISI (2013) Web of Science citations database (hereafter ISI). The paper analyses the 89 leading international journals in the ISI category of "Business - Finance” using quantifiable Research Assessment Measures (RAMs). The analysis highlights the similarities and differences in various RAMs, all of which are based on alternative transformations of journal citations and impact. Alternative RAMs may be calculated annually or updated daily to determine the citations frequency of published papers that are cited in journals listed in ISI. The RAMs include the classic 2-year impact factor including journal self citations (2YIF), 2-year impact factor excluding journal self citations (2YIF*), 5-year impact factor including journal self citations (5YIF), Immediacy including journal self citations, Eigenfactor (or Journal Influence), Article Influence, h-index, PI-BETA (Papers Ignored - By Even The Authors), Self-citation Threshold Approval Rating (STAR), 5YD2 (namely, 5YIF divided by 2YIF), Escalating Self Citations (ESC), and ICQ (Index of Citation Quality). The paper calculates the harmonic mean of the ranks of up to 16 RAMs. It is shown that emphasizing 2YIF to the exclusion of other informative RAMs can lead to a misleading evaluation of journal quality and impact relative to the harmonic mean of the ranks. The analysis of the 89 ISI journals in Finance makes it clear that there are three leading journals in Finance, namely Journal of Finance, Journal of Financial Economics and Review of Financial Studies, which form an exclusive club in terms of the RAMs that measure journal quality and impact based on alternative measures of journal citations. The next two journals in Finance in terms of overall quality and impact are Journal of Accounting and Economics and Journal of Monetary Economics.
\end{abstract}

Keywords: Research assessment measures, Impact factor, IFI, C3PO, PI-BETA, STAR, Eigenfactor, Article Influence, h-index, 5YD2, ICQ, ESC, harmonic mean of the ranks, finance, journal rankings.

JEL Classifications: C18, C81, Y10. 


\section{Introduction}

The perceived quality and impact of academic journals are important in evaluating the perceived research performance of individual researchers for hiring, tenure and promotion decisions. Rightly or wrongly, such perceived journal quality and impact are typically used as a proxy for the quality of an academic paper, as publication in a highly regarded journal is seen as imparting an important signal regarding the purported quality of the published paper.

The determination of the leading journals in any discipline can be based on a wide range of quantitative and qualitative assessments, ranging from expert (and possibly subjective) assessments of journal impact, evaluation of high quality and high impact articles, and the use of quantifiable bibliometric Research Assessment Measures (RAMs).

In the academic discipline of Finance, it is often a necessary condition to publish a certain number of papers in the top 3 journals in order to be given tenure and promotion, or to be appointed to a senior academic position. Therefore, the question raised in the title of the paper can be of great importance to establishing and maintaining an academic career in Finance.

The leading database for generating RAMs to evaluate the quality and impact of academic journals, as well as the research performance of individual researchers, is the Thomson Reuters ISI Web of Science (2013) database (hereafter ISI). Virtually all RAMs are based on alternative transformations of citations data.

As has been discussed widely in the literature, although there are important caveats regarding the methodology and data collection methods underlying any database, the ISI citations database is the oldest and most widely-used source of RAMs (see, for example, Chang et al. (2011a, b, c, d) and Chang et al. (2014) for caveats regarding ISI). It is widely held that the ISI database is a benchmark against which other general databases, such as SciVerse Scopus, Google Scholar and Microsoft Academic Search, social science open access repositories, such as the Social Science Research Network (SSRN), and discipline-specific databases, such as Research Papers in Economics (RePEc) (which also includes most journals in Finance and Accounting), are compared. 
Journal editors and publishers promote the ISI impact factors of their journals based on citations and, if their journals do not yet have an ISI impact factor, publicize the fact that their journals have either been selected for coverage in ISI, and hence are being tracked by ISI, or that the journal has applied for inclusion in ISI.

Various RAMs and weighting schemes have been used to compare the quality and impact of journals in a wide range of ISI disciplines, such as the 40 leading ISI journals in Economics (Chang et al. (2011a), Chang and McAleer (2014c)), the leading 10 ISI journals in each of Management, Finance and Marketing (Chang et al. (2011a)), the leading 6 ISI journals in each of 20 disciplines in the Sciences (Chang et al (2011b)), the leading ISI journals in Econometrics and Statistics (Chang et al. (2011c)), the leading 26 ISI journals in Neuroscience (Chang et al. (2011d)), the leading ISI journals in tourism and hospitality (Chang and McAleer (2012)), the leading ISI journals in Statistics \& Probability (Chang and McAleer (2013a)), a subset of the leading ISI journals in Finance based on survey responses (Chang and McAleer (2013b)), the 10 leading ISI and RePEc journals in Econometrics (Chang and McAleer (2013c, 2014c)), the leading ISI journals in agricultural, energy, environmental and resource economics (Chang and McAleer (2014a)), and the leading journals in the ISI discipline of Economics (Chang et al. (2014)).

Despite the wide selection of ISI and other journals across a number of disciplines that have been analysed to date, not all of the leading 89 journals in the ISI discipline of "Business Finance” have been analysed and ranked in terms of citations quality and impact. For this reason, one of the primary aims of this paper is to undertake such a rankings analysis, and to answer the question posed in the title of the paper.

The paper also evaluates the strong perception held in the Finance profession regarding the leading academic journals. There would be little or no disagreement that the leading academic journals are Journal of Finance, Journal of Financial Economics and Review of Financial Studies, followed by Journal of Financial and Quantitative Analysis. In fact, the survey results reported in Chang and McAleer (2013b) ranked Journal of Finance at number 1, followed closely by Journal of Financial Economics and Review of Financial Studies as equal number 2, and Journal of Financial and Quantitative Analysis as a distant number 4. Chang and McAleer (2013b) ranked 21 (34) ISI journals in Finance using 13 (10) RAMs, where the journals were selected by a panel of international experts. In this paper, we will rank 58 (88) 
ISI journals in Finance using 16 (13) RAMs using all the journals in the ISI category of "Business - Finance”.

This paper evaluates the usefulness of 16 RAMs for 89 leading ISI journals in Finance, and calculates the harmonic mean of the ranks of the alternative RAMs. Together with the arithmetic and geometric means, the harmonic mean is one of the three Pythagorean means, and is defined as the reciprocal of the arithmetic mean of the reciprocals. The rankings based on a single RAM is an extreme as it is subsumed in the harmonic mean of the ranks when all the other RAMs are given zero weights in the calculation (for further details see, for example, Chang and McAleer (2013a)).

The journals rankings presented in the paper suggest there are three leading journals in Finance, namely Journal of Finance, Journal of Financial Economics and Review of Financial Studies. These three journals form an exclusive club in terms of the RAMs that measure journal quality and impact based on journal citations. The next two journals in terms of overall quality and impact are Journal of Accounting and Economics and Journal of Monetary Economics.

The plan of the remainder of the paper is as follows. Section 2 presents some key RAMs using ISI data that may be calculated annually or updated daily, including the most widely used RAM, namely the classic 2-year impact factor including journal self citations (2YIF), 2year impact factor excluding journal self citations (2YIF*), 5-year impact factor including journal self citations (5YIF), Immediacy (or zero-year impact factor (0YIF)), Eigenfactor (or Journal Influence), Article Influence, C3PO (Citation Performance Per Paper Online), hindex, PI-BETA (Papers Ignored - By Even The Authors), 2-year Self-citation Threshold Approval Ratings (2Y-STAR), Historical Self-citation Threshold Approval Ratings (HSTAR), Impact Factor Inflation (IFI), Cited Article Influence (CAI), 5YD2 (5YIF Divided by 2YIF), ESC (Escalating Self Citations), and ICQ (Index of Citations Quality). Section 3 discusses and analyses 16 RAMs for 89 leading journals in the ISI category of "Business, Finance”, and provides a harmonic mean of the ranks as a robust rankings method of alternative RAMs. Section 4 summarizes the ranking outcomes and discusses some practical aspects of ranking journal quality and impact. 


\section{Research Assessment Measures (RAM)}

A widely-used RAM database for evaluating journal impact and quality based on citations is the Thomson Reuters ISI Web of Science (2013). As discussed in a number of papers (see, for example, Chang et al. (2011a, b, c) and Chang et al. (2014)), the RAMs are intended as descriptive statistics to capture journal quality and impact, and are not based on a mathematical model. Hence, in what follows, no optimization or estimation is required in calculating the alternative RAMs.

As the alternative RAMs that are provided in ISI and in several recent publications may not be widely known, this section provides a brief description and definition of 16 RAMs that may be calculated annually or updated daily (for further details see, for example, Chang et al. (2011a, b, c) and Chang et al. (2014)).

\subsection{Annual RAM}

With four exceptions, namely Eigenfactor, Article Influence (AI), Cited Article Influence (CAI) and Index of Citations Quality (ICQ), all existing RAMs are based on citations data and are reported separately for the sciences and social sciences. RAMs may be computed annually or updated daily. The annual RAMs given below are calculated for a Journal Citations Reports (JCR) calendar year, which is the year before the annual RAMs are released. For example, the most recent RAMs were released by ISI (2013) in late-June 2013 for the JCR calendar year 2012.

\section{(1) 2-year impact factor including journal self citations (2YIF):}

The classic 2-year impact factor including journal self citations (2YIF) of a journal is typically referred to as "the impact factor", is calculated annually, and is defined as "Total citations in a year to papers published in a journal in the previous 2 years / Total papers published in a journal in the previous 2 years”. The choice of 2 years by ISI is arbitrary. It is widely held in the academic community, and certainly by the editors and publishers of journals, that a higher 2YIF is better than lower.

\section{(2) 2-year impact factor excluding journal self citations (2YIF*):}


ISI also reports a 2-year impact factor without journal self citations (that is, citations to a journal in which a citing paper is published), which is calculated annually. As this impact factor is not widely known or used, Chang et al. (2011c) refer to this RAM as 2YIF*. Although 2YIF* is rarely reported, a higher value would be preferred to lower.

\section{(3) 5-year impact factor including journal self citations (5YIF):}

The 5-year impact factor including journal self citations (5YIF) of a journal is calculated annually, and is defined as "Total citations in a year to papers published in a journal in the previous 5 years / Total papers published in a journal in the previous 5 years.” The choice of 5 years by ISI is arbitrary. Although 5YIF is not widely reported, a higher value would be preferred to lower.

\section{(4) Immediacy, or zero-year impact factor including journal self citations (OYIF):} Immediacy is a zero-year impact factor including journal self citations (OYIF) of a journal, is calculated annually, and is defined as "Total citations to papers published in a journal in the same year / Total papers published in a journal in the same year.” The choice of the same year by ISI is arbitrary, but the nature of Immediacy makes it clear that a very short run outcome is under consideration. Although Immediacy is not frequently reported, a higher value would be preferred to lower.

\section{(5) 5YIF Divided by 2YIF (5YD2):}

As both 2YIF and 5YIF include journal self citations, if it is assumed that journal self citations are uniformly distributed over the 5-year period for calculating 5YIF, their ratio will eliminate the effect of journal self citations and capture the increase in the citation rate over time. In any event, the impact of journal self citations should be mitigated with the ratio of 5YIF to 2YIF. We define a new dynamic RAM as 5YD2 as "5YD2 = 5YIF / 2YIF". In the natural, physical and medical sciences, where citations are observed with a frequency of weeks and months rather than years, it is typically the case that 5YIF $<2$ YIF (see Chang et al. (2011b, d)), whereas the reverse, 5YIF > 2YIF, seems to hold generally in the social sciences, where citations tend to increase gradually over time (see Chang et al. (2011a, c)). Thus, emphasizing the different speeds at which citations are accrued over time, a lower 5YD2 would be preferred to higher in the sciences, while a higher 5YD2 would be preferred to lower in the social sciences. 


\section{(6) Eigenfactor (or Journal Influence):}

The Eigenfactor score (see Bergstrom (2007), Bergstrom and West (2008), Bergstrom, West and Wiseman (2008)) is calculated annually (see www.eigenfactor.org), and is defined as: "The Eigenfactor Score calculation is based on the number of times articles from the journal published in the past five years have been cited in the JCR year, but it also considers which journals have contributed these citations so that highly cited journals will influence the network more than lesser cited journals. References from one article in a journal to another article from the same journal are removed, so that Eigenfactor Scores are not influenced by journal self-citation.” The value of the threshold that separates 'highly cited' from 'lesser cited' journals, as well as how the former might 'influence the network more' than the latter, are based on the Eigenfactor score of the citing journal. Thus, Eigenfactor might usefully be interpreted as a weighted total citations score, or a "Journal Influence” measure. A higher Eigenfactor score would be preferred to lower.

\section{(7) Article Influence (or Journal Influence per Article):}

Article Influence (see Bergstrom (2007), Bergstrom and West (2008), Bergstrom, West and Wiseman (2008)) measures the relative importance of a journal's citation influence on a perarticle basis. Despite the misleading suggestion of measuring “Article Influence”, as each journal has only a single "Article Influence" score, this RAM is actually a "Journal Influence per Article” score. Article Influence is a scaled Eigenfactor score, is calculated annually, is standardized to have a mean of one across all journals in the Thomson Reuters ISI database, and is defined as "Eigenfactor score divided by the fraction of all articles published by a journal.” A higher Article Influence would be preferred to lower.

\section{(8) IFI:}

The ratio of 2YIF to 2YIF* is intended to capture how journal self citations can inflate the impact factor of a journal, whether this is an unconscious self-promotion decision made independently by publishing authors or as an administrative decision undertaken by a journal's editors and/or publishers. Chang et al. (2011a) define Impact Factor Inflation (IFI) as "IFI = 2YIF / 2YIF*". The minimum value for IFI is 1 , with any value above the minimum capturing the effect of journal self citations on the 2-year impact factor. A lower IFI would be preferred to higher.

\section{(9) H-STAR:}


ISI has implicitly recognized the inflation in journal self citations by calculating an impact factor that excludes self citations, and provides data on journal self citations, both historically (for the life of the journal) and for the preceding two years, in calculating 2YIF. Chang et al. (2011b) define the Self-citation Threshold Approval Rating (STAR) as the percentage difference between citations in other journals and journal self citations. If HS = historical journal self citations, then Historical STAR (H-STAR) is defined as "H-STAR $=[(100-H S)$ $\mathrm{HS}]=(100-2 \mathrm{HS})$ ". If HS = 0 (minimum), 50 or 100 (maximum) percent, for example, $\mathrm{H}-$ STAR $=100,0$ and -100 , respectively. A higher H-STAR would be preferred to lower.

\section{(10) 2Y-STAR:}

H-STAR examines the self-citation threshold approval rating over the historical period for which data for a journal are available, namely from the inclusion of the journal in ISI, whereas 2Y-STAR examines the self-citation threshold approval rating based on data for the preceding two years. If $2 \mathrm{YS}$ = journal self citations over the preceding 2-year period, then the 2-Year STAR is defined by Chang et al. (2011b) as "2Y-STAR $=[(100-2 Y S)-2 Y S]=(100-$ 2(2YS))”. If 2YS = 0 (minimum), 50 or 100 (maximum) percent, for example, 2Y-STAR = 100, 0 and -100, respectively. A higher 2Y-STAR would be preferred to lower.

\section{(11) Escalating Self Citations (ESC):}

As self citations for many journals in the sciences and social sciences have been increasing over time, it would seem useful to present a dynamic RAM that captures such an escalation over time. The difference given by 2YS - HS measures Escalating Self Citations in journals over the most recent 2 years relative to the historical period for calculating citations, which will differ across journals. We define a new dynamic RAM as "ESC $=2 \mathrm{YS}-\mathrm{HS}=(\mathrm{H}-$ STAR - 2Y-STAR) / 2”. Given the range of each of H-STAR and 2Y-STAR is $(-100,100)$, the range of ESC is also $(-100,100)$, with -100 denoting minimum, and 100 denoting maximum, escalation. A lower ESC would be preferred to higher.

\section{(12) Index of Citations Quality (ICQ):}

Wilhite and Fong (2012) and Chang, et al. (2013), among others, have argued the well-known practice of coercive journal citations by both editors and publishers distorts the intended meaning and interpretation of journal impact and influence. Chang and McAleer (2014b, c) suggested the following Index of Citations Quality (ICQ) to try to evaluate the impact of coercive self citations: "ICQ $=$ AI / 5YIF $=$ Quality Weighted Citations / Total Citations = 
"Quality weighted citations in the past 5 years, excluding journal self citations" / "Total citations in the previous 5 years, including journal self citations”. A higher ICQ would generally be preferred to lower.

\subsection{Daily Updated RAM}

Some RAMs are updated daily, and are reported for a given day in a calendar year rather than for a JCR year.

\section{(13) C3PO:}

ISI reports the mean number of citations for a journal, namely total citations up to a given day divided by the number of papers published in a journal up to the same day, as the "average" number of citations. In order to distinguish the mean from the median and mode, the C3PO of an ISI journal on any given day is defined by Chang et al. (2011a) as "C3PO (Citation Performance Per Paper Online) $=$ Total citations to a journal $/$ Total papers published in a journal.” A higher C3PO would be preferred to lower. [Note: C3PO should not be confused with C-3PO, the Star Wars android.]

\section{(14) h-index:}

The h-index (Hirsch, 2005)) was originally proposed to assess the scientific research productivity and citations impact of individual researchers. However, the h-index can also be calculated for journals, and should be interpreted as assessing the impact or influence of highly cited journal publications. The h-index of a journal on any given day is based on historically cited and citing papers, including journal self citations, and is defined as "h-index = number of published papers, where each has at least $\mathrm{h}$ citations.” The h-index differs from an impact factor in that the h-index measures the number of highly cited papers historically. A higher h-index would be preferred to lower.

\section{(15) PI-BETA:}

This RAM measures the proportion of papers in a journal that has never been cited, As such, PI-BETA is, in effect, a rejection rate of a journal after publication. Chang et al. (2011c) argue that lack of citations of a published paper, especially if it is not a recent publication, reflects on the quality of a journal by exposing: (i) what might be considered as incorrect decisions by the members of the editorial board of a journal; and (ii) the lost opportunities of 
papers that might have been cited had they not been rejected by the journal. Chang et al. (2011c) propose that a paper with zero citations in ISI journals can be measured by PI-BETA (= Papers Ignored (PI) - By Even The Authors (BETA)), which is calculated for an ISI journal on any given day as "Number of papers with zero citations in a journal / Total papers published in a journal.” As journals would typically prefer a higher proportion of published papers being cited rather than ignored, a lower PI-BETA would be preferred to higher.

\section{(16) CAI:}

Article Influence is intended to measure the average influence of an article across the sciences and social sciences. As an article with zero citations typically does not have any (academic) influence, a more suitable measure of the influence of cited articles would seem to be Cited Article Influence (CAI). Chang et al. (2011b) define CAI as "CAI = (1 - PIBETA)(Article Influence)". If PI-BETA $=0$, then CAI is equivalent to Article Influence; if PI-BETA $=1$, then CAI $=0$. As Article Influence is calculated annually and PI-BETA is updated daily, CAI may be updated daily. A higher CAI would be preferred to lower.

\section{Analysis of RAM for 89 Leading ISI Journals in Finance}

As has been argued in the literature, no single RAM captures adequately the quality and impact of a journal. Therefore, any measure of journal quality and impact is based on an arbitrarily chosen weighted mean, such as the harmonic mean of the ranks of the alternative RAMs. All RAMs are ranked from high to low, apart from IFI, PI-BETA and ESC, which are ranked from low to high.

The ISI category of Finance is listed under the discipline of "Business - Finance" (specifically, "Business, Finance”), and contains 89 journals. We compare the RAMs that are based on ISI citations data. Only articles from the ISI Web of Science are included in the citations database, which were downloaded from ISI on 14 May 2014 for all journals. The ISI data set starts in 1899, so all data are from the inclusion of the respective journals in ISI, except for Forbes, where 2004 is the first year in which the number of articles is below 10,000, which is the upper limit for which daily RAM (namely, h-index, C3PO, PI-BETA and CAI) are reported in ISI). 
Some comments on the 89 journals in the ISI category of "Business - Finance" are in order. JASSA - The Finsia Journal of Applied Finance has zero entries for 2YIF, 2YIF* and Immediacy, and hence is excluded from the rankings analysis (but not from the discussion of the data in Table 1). Of the remaining 88 journals listed in ISI in Table 1 below, 30 journals have no data for Article Influence, and hence no data for CAI and ICQ. Therefore, data for all 16 RAMs are available for 58 journals, while data for 13 RAMs are available for 88 journals.

Table 1 presents 16 RAMs for the 89 leading journals in "Business - Finance" (hereafter "Finance"), which are ranked according to 2YIF. The means and ranges of 2YIF are, respectively, 1.006 and $(0,4.333)$, of 2YIF* are 0.806 and $(0,3.984)$, of 5YIF are 1.424 and (0.036, 6.185), and of Immediacy are 0.171 and $(0,0.867)$. These alternative impact factors are generally consistent with the related areas of both Management and Marketing (see Chang et al. (2011a)), but are typically considerably lower than many ISI disciplines in the sciences (see Chang et al. (2011b)). There are 14 journals with Immediacy of zero, which means there were no citations to these journals in the year of their publication. The mean and range of 5YD2 are 1.577 and $(0.49,4.71)$, respectively, so that 5YIF is considerably higher than 2YIF, which means that citations increase as the citations period is extended from two to five years.

Journal self citations in Finance seem to be very high, with a mean IFI of 1.679 and a range of $(1,27.8)$, in comparison with a mean IFI of 1.442 for 299 Economics journals in ISI (see Chang et al. (2014)). There are 10 IFI values in excess of 2, and 3 IFI values in excess of 3 , with the highest being an extraordinary 27.8. On average, the 89 leading journals in Finance have 2YIF that is inflated by a factor of 1.679 through journal self citations. It is also worth mentioning that 12 of the 89 journals have zero self citations.

The h-index has a mean of 29 and a range of $(2,204)$, with Journal of Finance being the highest at 204, followed by Journal of Financial Economics at 179, Journal of Monetary Economics at 115, and Review of Financial Studies at 109. There are 14 journals with an hindex not greater than 10 .

In terms of mean citations, C3PO has a mean of 7.406 and a range of $(0.02,72.57)$, with a significant contribution coming from Journal of Financial Economics. Eigenfactor has a mean of 0.00454 and a range of $(0.00001,0.06476)$, with 3 journals, Review of Financial Studies, 
Journal of Financial Economics and Journal of Finance, clearly having the highest scores, and hence the greatest Journal Influence.

Article Influence has a mean of 1.363 and a range of $(0.034,8.824)$, with the same 3 journals having the greatest journal influence. As Article Influence is standardized to have a mean of one across all science and social science journals in the Thomson Reuters ISI database, the mean article influence in Finance is greater than for all the journals in the ISI database. Cited Article Influence (CAI) has a mean of 1.025 and a range of $(0.001,6.46)$, with the same 3 journals having the highest influence on the basis of cited journal articles.

For purposes of comparing quality versus quantity citations, ICQ has a mean of 0.719 and a range of $(0.109,1.772)$. As the mean is well below 1 , on average the journals in Finance have citations quantity that exceeds the respective citations quality. The mean ICQ for Finance is only slightly higher than the mean ICQ of 0.679 for 276 Economics journals in ISI, though considerably lower than the mean ICQ of 1.255 for the leading 10 ISI journals in econometrics (see Chang and McAleer (2014c)).

The means and ranges for H-STAR and 2Y-STAR for the 89 journals are 71 and $(-64,100)$, and 57 and $(-92,100)$, respectively. The H-STAR and 2Y-STAR means of 71 and 57 reflect journal self citations of $14.5 \%$ and $21.5 \%$, respectively, historically and for the preceding two years. On average, journal self citations have increased over the preceding two years as compared with historical levels. The ESC mean is 7 and has a range of $(-13,46)$. On average, self citations are escalating, with 14 journals having no change in the preceding 2 years relative to historical levels, 15 journals decreasing in self citations, and 59 journals increasing in self citations. Overall, two-thirds of the ISI journals in Finance have escalating self citations relative to historical levels.

The PI-BETA scores are illuminating. The mean is 0.396 so that, on average, 2 of every 5 papers that are published in the leading 89 journals in Finance is not cited. The range of (0.082, 0.982) suggests that the journal with the highest percentage of cited papers has one uncited paper for every 12 published papers, while the journal with the lowest percentage of cited papers has virtually no cited papers. The mean PI-BETA value in Table 1 is lower than the mean PI-BETA for 299 ISI journals in Economics (see Chang et al. (2014)). 
The simple correlations of 16 RAMs for the 58 leading journals in Finance are given in Table 2, while the simple correlations of 13 RAMs for the 88 leading journals are given in Table 3. In Tables 2 and 3, there are 7 and 2 RAM pairs for which the correlations exceed 0.9 (in absolute value), respectively, and 15 and 7 RAM pairs, respectively, for which the correlations are in the range $(0.8,0.9)$, in absolute value. The correlations of 0.974 and 0.971 between 2YIF and 2YIF* in Tables 2 and 3, respectively, are very high, which indicates that the 2-year impact factors including and excluding self citations are very similar for the leading Finance journals in ISI. A similar comment applies to the very high correlation for the pairs (Article Influence, CAI) and (IFI, 2Y-STAR) in Table 2. The lower correlations for many other pairs of RAMs suggest that they provide additional information about the citations impact of journals in Finance.

In order to answer the question posed in the title of the paper, as well as to examine if reliance on 2YIF to the exclusion of the other RAMs can lead to a distorted evaluation of journal quality and impact, a robust ranking of the 88 leading journals in Finance given in Table 1 will be based on the harmonic mean of the ranks (see, for example, Chang and McAleer (2013a)).

In Table 4, the harmonic mean (HM) is calculated based on the ranks of 14 RAMs of the 58 leading Finance journals. As H-STAR and 2Y-STAR had 9 and 12 journals, respectively, with equal highest rank, it was not possible to discriminate accurately among the journals. For this reason, these two RAMs are not included in the calculation of HM. The journals in Table 4 are ranked according to HM. The leading 4 journals are Journal of Finance, Journal of Financial Economics, Review of Financial Studies, and Journal of Accounting and Economics. In comparison with the rankings in Table 1 that are based on 2YIF, only Journal of Finance remains unchanged at number 1, but the other three journals remain in the top 4 .

Abacus is ranked number 5 (previously 36 based on 2YIF) because it is ranked number 1 using both IFI and ESC, but is ranked 50 or lower using four separate RAMs. Journal of Monetary Economics is ranked 6 (previously 12 based on 2YIF), but its range of ranks is (3, 38). Journal of Financial and Quantitative analysis is ranked 15 (previously 13 based on 2YIF), with a range of ranks of $(7,31)$. 
Of the leading 10 journals according to 2YIF in Table 1, 6 journals have remained in the top 10 according to HM. The 4 journals to have slipped out of the top 10 have remained in the top 20 at 13, 17, 18 and 19.

The journal to have shifted the largest number of positions is Forbes, which moved from 56, based on 2YIF, to 14 based on HM, primarily because of equal highest ranking using IFI. Indeed, four other large movers are ranked in the top 12 primarily because of their equal highest score using IFI.

As has been argued elsewhere, the harmonic mean of the ranks tends to reward journals with very strong individual performances according to a small number of RAMs, so that even one very strong ranking of a RAM can lead to a greatly improved ranking. A choice among the harmonic, geometric or arithmetic means of the ranks as the most appropriate Pythagorean mean of the ranks leads to an arbitrary choice of weights. The RAMs provided in Tables 1 and 4 allow alternative weights to be used for different journals, but concentration on an individual RAM, such as 2YIF, with zero weights imposed on all other RAMs, is not only highly restrictive, but also potentially misleading as a measure of journal quality and impact.

In Table 5, the harmonic mean (HM) is calculated based on the ranks of 10 RAMs of the 88 leading Finance journals. As in the case of Table 4, IFI, H-STAR and 2Y-STAR had 12, 9 and 12 journals, respectively, with equal highest rank, so it was not possible to discriminate accurately among the journals. For this reason, these three RAMs are not included in the calculation of HM. The journals in Table 5 are ranked according to HM. The leading 4 journals are again Journal of Finance, Journal of Financial Economics, Review of Financial Studies, and Journal of Accounting and Economics, which is the same ordering as in Table 4.

The number 5 ranking in Table 5 is Accounting Auditing \& Accountability Journal, with three RAMs ranked worse than 60 and a range of rankings of $(2,70)$, which is a significant change from its ranking of 40 according to 2YIF. The number 6 ranking is Journal of Monetary Economics, with a range of rankings of $(3,54)$ and only one RAM ranked worse than 40 .

The Journal of Risk Model Validation has moved from 88 based on 2YIF to 7 based on HM, primarily because of having the highest ranking using 5YD2, while International Insolvency 
Review has moved from 85 to 8 based on having the highest ranking using ESC. These two journals were not ranked in Table 4 because they had no data on Article Influence, CAI and ICQ.

The simple ranking correlations of the 14 RAMs for the 58 leading journals in Finance, based on the rankings in Table 4, are given in Table 6. The correlations in Table 6 are not very close (in absolute value) to the correlations in Table 2 for the original RAM scores. There are 3 RAM pairs for which the correlations exceed 0.9 (in absolute value), with the highest correlation being for the pair (Article Influence, CAI) at 0.979, which suggests that the rankings according to Article Influence and CAI would be virtually identical.

In Table 6, the two highest correlations of RAMs with the Harmonic Mean are for Article Influence (at 0.713) and CAI (at 0.709), which are much higher than the correlation of 2YIF with HM at 0.568 . Thus, 2YIF would clearly not be the most robust individual RAM if it were intended to capture HM. In this sense, using 2YIF as a single RAM to capture the quality and impact of a journal would lead to a misleading evaluation of its impact and influence.

The simple ranking correlations of the 11 RAMs for the 88 leading journals in Finance, based on the rankings in Table 5, are given in Table 7. The correlations in Table 7 are not very close (in absolute value) to the correlations in Table 3 for the original RAM scores. There are 3 RAM pairs for which the correlations exceed 0.9 (in absolute value), with the highest correlation being for the pair (h-index, C3PO) at 0.955, which suggests that the rankings according to h-index and C3PO would be virtually identical.

In Table 7, the two highest correlations of RAMs with the Harmonic Mean are for 2YIF* (at 0.69) and 5YIF (at 0.673), which are only slightly higher than the correlation of 2YIF with $\mathrm{HM}$ at 0.612 . Thus, 2YIF would not be entirely misleading it were used to try to capture HM. In this sense, using $2 \mathrm{YIF}$ as a single RAM to capture the quality and impact of a journal would not necessarily lead to a misleading evaluation of its impact and influence.

\section{Concluding Remarks}


The paper evaluated the ranking of academic journal quality and research impact using the Thomson Reuters ISI Web of Science (2013) citations database (hereafter ISI) for the "Business - Finance" category. This paper analysed the leading 89 journals in the Finance using 16 quantifiable Research Assessment Measures (RAMs). The 16 RAMs that may be calculated annually or updated daily are used to rank journal quality and impact.

The paper highlighted the similarities and differences in alternative RAMs, and showed that several RAMs were highly correlated so that they had little informative incremental value in capturing the impact and performance of the highly-cited journals. Other RAMs were not highly correlated with each other, which meant they contained useful additional information. The harmonic mean of a subset of the ranks of the 16 RAMs were also presented for the leading Finance journals in ISI to provide robust journals rankings of quality and impact.

It was shown that emphasizing 2YIF of a journal to the exclusion of several other informative RAMs could lead to a misleading evaluation of journal quality and impact relative to the harmonic mean of the ranks of RAMs.

A similar comment would apply to emphasizing any individual RAM, with zero weights imposed on all other RAMs. Using such a rankings approach would not only be highly restrictive, but it would also be potentially misleading as a robust measure of journal quality and impact.

The journals rankings presented above indicate clearly that there are three leading journals in Finance, namely Journal of Finance, Journal of Financial Economics and Review of Financial Studies. These three journals form an exclusive club in terms of the RAMs that measure journal quality and impact based on alternative measures of journal citations. The next two journals in terms of overall quality and impact are Journal of Accounting and Economics and Journal of Monetary Economics. The Journal of Financial and Quantitative Analysis is not in the top 10 journals in Finance, despite a widely-held perception in the discipline that it might be just outside the top 3 journals. 


\section{References}

Bergstrom C. (2007), Eigenfactor: Measuring the value and prestige of scholarly journals, C\&RL News, 68, 314-316.

Bergstrom, C.T. and. J.D. West (2008), Assessing citations with the Eigenfactor ${ }^{\mathrm{TM}}$ metrics, Neurology, 71, 1850-1851.

Bergstrom, C.T., J.D. West and M.A. Wiseman (2008), The Eigenfactor ${ }^{\mathrm{TM}}$ metrics, Journal of Neuroscience, 28(45), 11433-11434 (November 5, 2008).

Chang, C.-L. and M. McAleer (2012), Citations and impact of ISI tourism and hospitality journals, Tourism Management Perspectives, 1(1), 2-8.

Chang, C.-L. and M. McAleer (2013a), Ranking journal quality by harmonic mean of ranks: An application to ISI statistics \& probability, Statistica Neerlandica, 67(1), 27-53.

Chang, C.-L. and M. McAleer (2013b), What do experts know about forecasting journal quality? A comparison with ISI research impact in finance, Annals of Financial Economics, 8(1), 1-30.

Chang, C.-L. and M. McAleer (2013c), Ranking leading econometrics journals using citations data from ISI and RePEc, Econometrics, 1, 217-235.

Chang, C.-L. and M. McAleer (2014a), How should journal quality be ranked? An application to agricultural, energy, environmental and resource economics, Journal of Reviews on Global Economics, 3, 33-47.

Chang, C.-L. and M. McAleer (2014b), Quality weighted citations versus total citations in the sciences and social sciences, Tinbergen Institute Discussion Paper 14-023/III, Tinbergen Institute, The Netherlands.

Chang, C.-L. and M. McAleer (2014c), Ranking economics and econometrics ISI journals by quality weighted citations, to appear in Review of Economics.

Chang, C.-L., E. Maasoumi and M. McAleer (2014), Robust ranking of journal quality: An application to economics, to appear in Econometric Reviews.

Chang, C.-L., M. McAleer and L. Oxley (2011a), What makes a great journal great in economics? The singer not the song, Journal of Economic Surveys, 25(2), 326-361.

Chang, C.-L., M. McAleer and L. Oxley (2011b), What makes a great journal great in the sciences? Which came first, the chicken or the egg?, Scientometrics, 87(1), 17-40.

Chang, C.-L., M. McAleer and L. Oxley (2011c), Great expectatrics: Great papers, great journals, great econometrics, Econometric Reviews, 30(6), 583-619. 
Chang, C.-L., M. McAleer and L. Oxley (2011d), How are journal impact, prestige and article influence related? An application to neuroscience, Journal of Applied Statistics, 38(11), 2563-2573.

Chang, C.-L., M. McAleer and L. Oxley (2013), Coercive journal self citations, impact factor, journal influence and article influence, Mathematics and Computers in Simulation, 93, 190197.

Hirsch, J.E. (2005), An index to quantify an individual's scientific research output, Proceedings of the National Academy of Sciences of the United States of America, 102(46), 16569-15572 (November 15, 2005).

ISI Web of Science (2013), Journal Citation Reports, Essential Science Indicators, Thomson Reuters ISI.

Wilhite, A.W . and E.A. Fong (2012), Coercive citation in academic publishing, Science, 335 (6068), 542-543. 
Table 1

16 Research Assessment Measures (RAM) for 89 Leading Finance Journals

\begin{tabular}{|c|c|c|c|c|c|c|c|c|c|c|c|c|c|c|c|c|}
\hline Journal & 2YIF & 2YIF* & IFI & 5YIF & $\begin{array}{c}\text { Imme- } \\
\text { diacy }\end{array}$ & 5YD2 & $\begin{array}{c}\text { h- } \\
\text { index }\end{array}$ & СЗРО & $\begin{array}{c}\text { PI- } \\
\text { BETA }\end{array}$ & $\begin{array}{l}\text { Eigen- } \\
\text { factor }\end{array}$ & AI & CAI & ICQ & $\begin{array}{c}\text { H- } \\
\text { STAR }\end{array}$ & $\begin{array}{c}\text { 2Y- } \\
\text { STAR }\end{array}$ & ESC \\
\hline J FINANC & 4.333 & 3.984 & 1.088 & 6.185 & 0.867 & 1.427 & 204 & 31.11 & 0.354 & 0.05733 & 8.824 & 5.7 & 1.427 & 96 & 94 & 1 \\
\hline J ACCOUNT ECON & 3.912 & 3.294 & 1.188 & 4.023 & 0.289 & 1.028 & 96 & 42.7 & 0.085 & 0.00741 & 2.453 & 2.244 & 0.61 & 82 & 70 & 6 \\
\hline J FINANC ECON & 3.424 & 3.038 & 1.127 & 5.087 & 0.669 & 1.486 & 179 & 72.57 & 0.082 & 0.05835 & 6.327 & 5.808 & 1.244 & 88 & 78 & 5 \\
\hline REV FINANC STUD & 3.256 & 2.863 & 1.137 & 5.367 & 0.421 & 1.648 & 109 & 37.75 & 0.108 & 0.06476 & 7.242 & 6.46 & 1.349 & 88 & 76 & 6 \\
\hline IMF ECON REV & 2.529 & 2.206 & 1.146 & 2.559 & 0 & 1.012 & 11 & 3.72 & 0.419 & 0.00248 & 4.172 & 2.424 & 1.63 & 74 & 76 & -1 \\
\hline ACCOUNT REV & 2.319 & 1.743 & 1.33 & 3.204 & 0.603 & 1.382 & 82 & 6.25 & 0.568 & 0.00795 & 1.474 & 0.637 & 0.46 & 74 & 52 & 11 \\
\hline IMF STAFF PAPERS & 2.312 & 2.312 & 1 & 1.344 & 0 & 0.581 & 29 & 9.24 & 0.147 & 0.00244 & 1.454 & 1.24 & 1.082 & 100 & 100 & 0 \\
\hline J FINANC INTERMED & 2.208 & 2.132 & 1.036 & 2.46 & 0.107 & 1.114 & 40 & 14.37 & 0.204 & 0.00582 & 2.688 & 2.14 & 1.093 & 94 & 94 & 0 \\
\hline J ACCOUNT RES & 2.192 & 1.863 & 1.177 & 3.368 & 0.256 & 1.536 & 88 & 20.85 & 0.196 & 0.00703 & 2.21 & 1.777 & 0.656 & 90 & 70 & 10 \\
\hline ACCOUNT ORG SOC & 1.867 & 1.44 & 1.297 & 3.143 & 0.125 & 1.683 & 68 & 20.81 & 0.095 & 0.00364 & 1.028 & 0.93 & 0.327 & 76 & 56 & 10 \\
\hline $\begin{array}{l}\text { J RISK } \\
\text { UNCERTAINTY }\end{array}$ & 1.771 & 1.25 & 1.417 & 2.016 & 0.167 & 1.138 & 53 & 25.16 & 0.109 & 0.0036 & 1.625 & 1.448 & 0.806 & 86 & 58 & 14 \\
\hline J MONETARY ECON & 1.649 & 1.491 & 1.106 & 2.529 & 0.163 & 1.534 & 115 & 30.83 & 0.164 & 0.02718 & 3.742 & 3.128 & 1.48 & 96 & 82 & 7 \\
\hline $\begin{array}{l}\text { J FINANC QUANT } \\
\text { ANAL }\end{array}$ & 1.636 & 1.579 & 1.036 & 2.13 & 0.214 & 1.302 & 79 & 15.39 & 0.206 & 0.01169 & 2.645 & 2.1 & 1.242 & 98 & 94 & 2 \\
\hline $\begin{array}{l}\text { CONTEMP ACCOUNT } \\
\text { RES }\end{array}$ & 1.564 & 1.385 & 1.129 & 2.154 & 0.186 & 1.377 & 31 & 8.79 & 0.28 & 0.00348 & 1.094 & 0.788 & 0.508 & 80 & 78 & 1 \\
\hline J FINANC STABIL & 1.463 & 0.878 & 1.666 & 1.568 & 0.208 & 1.072 & 13 & 3.33 & 0.386 & 0.00095 & - & - & - & 42 & 20 & 11 \\
\hline REV FINANC & 1.44 & 1.4 & 1.029 & 2.456 & 0.357 & 1.706 & 17 & 4.41 & 0.372 & 0.00477 & - & - & - & 96 & 96 & 0 \\
\hline CORP GOV-OXFORD & 1.4 & 0.431 & 3.248 & 1.581 & 0.156 & 1.129 & 11 & 2.77 & 0.388 & 0.00164 & 0.364 & 0.223 & 0.23 & 42 & -38 & 40 \\
\hline $\begin{array}{l}\text { MANAGE ACCOUNT } \\
\text { RES }\end{array}$ & 1.366 & 0.878 & 1.556 & 2.531 & 0.118 & 1.853 & 11 & 4.4 & 0.317 & 0.00105 & - & - & - & 68 & 30 & 19 \\
\hline REV ACCOUNT STUD & 1.364 & 1.2 & 1.137 & 1.899 & 0.219 & 1.392 & 27 & 8.45 & 0.304 & 0.00231 & 1.214 & 0.845 & 0.639 & 82 & 76 & 3 \\
\hline FINANC MANAGE & 1.33 & 0.907 & 1.466 & 1.568 & 0.235 & 1.179 & 46 & 8.52 & 0.219 & 0.00345 & 1.069 & 0.835 & 0.682 & 80 & 38 & 21 \\
\hline
\end{tabular}




\begin{tabular}{|c|c|c|c|c|c|c|c|c|c|c|c|c|c|c|c|c|}
\hline Journal & 2YIF & 2 YIF* $^{*}$ & IFI & 5YIF & Immediacy & 5YD2 & $\begin{array}{c}\text { h- } \\
\text { index }\end{array}$ & CЗPO & $\begin{array}{c}\text { PI- } \\
\text { BETA }\end{array}$ & Eigenfactor & $\begin{array}{c}\text { Article } \\
\text { Influence }\end{array}$ & CAI & ICQ & $\begin{array}{c}\text { H- } \\
\text { STAR }\end{array}$ & $\begin{array}{c}\text { 2Y- } \\
\text { STAR }\end{array}$ & ESC \\
\hline $\begin{array}{l}\text { WORLD BANK } \\
\text { ECON REV }\end{array}$ & 1.325 & 1.3 & 1.019 & 2.704 & 0.143 & 2.041 & 58 & 20.93 & 0.238 & 0.00398 & 2.111 & 1.609 & 0.781 & 98 & 98 & 0 \\
\hline ACCOUNT HORIZ & 1.288 & 1.058 & 1.217 & 2.128 & 0.333 & 1.652 & 11 & 2.69 & 0.429 & 0.00117 & - & - & - & 70 & 66 & 2 \\
\hline J BANK FINANC & 1.287 & 0.821 & 1.568 & 1.721 & 0.212 & 1.337 & 74 & 10.76 & 0.142 & 0.01566 & 0.796 & 0.683 & 0.463 & 64 & 38 & 13 \\
\hline J RISK INSUR & 1.237 & 0.724 & 1.709 & 1.39 & 0.116 & 1.124 & 38 & 4.11 & 0.487 & 0.00225 & 0.643 & 0.33 & 0.463 & 44 & 18 & 13 \\
\hline FINANC STOCH & 1.212 & 1.096 & 1.106 & 1.597 & 0.267 & 1.318 & 29 & 11.34 & 0.174 & 0.00381 & 1.761 & 1.455 & 1.103 & 80 & 82 & -1 \\
\hline J IND ECON & 1.194 & 1.09 & 1.095 & 1.539 & 0.192 & 1.289 & 70 & 16.2 & 0.178 & 0.0054 & 1.85 & 1.521 & 1.202 & 98 & 84 & 7 \\
\hline J FINANC SERV RES & 1.176 & 0.735 & 1.6 & 1.711 & 0.632 & 1.455 & 24 & 5.95 & 0.303 & 0.00098 & - & - & - & 70 & 26 & 22 \\
\hline EMERG MARK REV & 1.167 & 0.479 & 2.436 & 1.603 & 0.361 & 1.374 & 8 & 2.18 & 0.385 & 0.00034 & - & - & - & 26 & -16 & 21 \\
\hline $\begin{array}{l}\text { J MONEY CREDIT } \\
\text { BANK }\end{array}$ & 1.104 & 0.983 & 1.123 & 1.7 & 0.31 & 1.54 & 72 & 11.73 & 0.278 & 0.0127 & 1.691 & 1.221 & 0.995 & 88 & 80 & 4 \\
\hline J FINANC MARK & 1.093 & 0.977 & 1.119 & 1.505 & 0.222 & 1.377 & 22 & 10.44 & 0.226 & 0.00316 & 1.692 & 1.31 & 1.124 & 88 & 80 & 4 \\
\hline J CORP FINANC & 1.035 & 0.648 & 1.597 & 1.774 & 0.16 & 1.714 & 38 & 9.87 & 0.236 & 0.00502 & 1.05 & 0.802 & 0.592 & 72 & 26 & 23 \\
\hline $\begin{array}{l}\text { REAL ESTATE } \\
\text { ECON }\end{array}$ & 1.02 & 0.88 & 1.159 & 1.307 & 0.118 & 1.281 & 30 & 9.52 & 0.156 & 0.00172 & 0.777 & 0.656 & 0.594 & 74 & 74 & 0 \\
\hline $\begin{array}{l}\text { AUDITING-J PRACT } \\
\text { TH }\end{array}$ & 1.015 & 0.612 & 1.658 & 1.408 & 0.2 & 1.387 & 36 & 8.42 & 0.248 & 0.0011 & 0.483 & 0.363 & 0.343 & 54 & 22 & 16 \\
\hline $\begin{array}{l}\text { J BUS FINAN } \\
\text { ACCOUNT }\end{array}$ & 1.01 & 0.33 & 3.061 & 1.061 & 0.128 & 1.05 & 21 & 4.83 & 0.229 & 0.00144 & 0.313 & 0.241 & 0.295 & 58 & -34 & 46 \\
\hline MATH FINANC & 1 & 0.919 & 1.088 & 1.463 & 0.375 & 1.463 & 44 & 19.94 & 0.142 & 0.00382 & 1.486 & 1.275 & 1.016 & 90 & 86 & 2 \\
\hline $\begin{array}{l}\text { J FINANC } \\
\text { ECONOMET }\end{array}$ & 0.976 & 0.881 & 1.108 & 1.58 & 0.091 & 1.619 & 13 & 4.12 & 0.387 & 0.00301 & 1.724 & 1.057 & 1.091 & 80 & 82 & -1 \\
\hline FINANC ANAL J & 0.952 & 0.603 & 1.579 & 0.959 & 0.412 & 1.007 & 27 & 3.6 & 0.566 & 0.00234 & 0.789 & 0.342 & 0.823 & 88 & 28 & 30 \\
\hline J EMPIR FINANC & 0.934 & 0.818 & 1.142 & 1.626 & 0.12 & 1.741 & 14 & 3.3 & 0.362 & 0.00478 & - & - & - & 90 & 76 & 7 \\
\hline J REAL ESTATE RES & 0.925 & 0.525 & 1.762 & 1.069 & 0.381 & 1.156 & 10 & 3.48 & 0.238 & 0.0009 & 0.511 & 0.389 & 0.478 & 44 & 14 & 15 \\
\hline $\begin{array}{l}\text { ACCOUNT AUDIT } \\
\text { ACCOUN }\end{array}$ & 0.922 & 0.675 & 1.366 & 4.039 & 0.386 & 4.381 & 8 & 1.68 & 0.544 & 0.00133 & - & - & - & 28 & 48 & -10 \\
\hline
\end{tabular}




\begin{tabular}{|c|c|c|c|c|c|c|c|c|c|c|c|c|c|c|c|c|}
\hline Journal & 2YIF & 2YIF* & IFI & 5YIF & Immediacy & 5YD2 & $\begin{array}{c}\text { h- } \\
\text { index }\end{array}$ & СЗРО & $\begin{array}{c}\text { PI- } \\
\text { BETA }\end{array}$ & Eigenfactor & $\begin{array}{c}\text { Article } \\
\text { Influence }\end{array}$ & CAI & ICQ & $\begin{array}{c}\text { H- } \\
\text { STAR }\end{array}$ & $\begin{array}{l}\text { 2Y- } \\
\text { STAR }\end{array}$ & ESC \\
\hline INT J CENT BANK & 0.895 & 0.807 & 1.109 & 1.295 & 0.088 & 1.447 & 10 & 1.85 & 0.543 & 0.00203 & - & - & - & 92 & 82 & 5 \\
\hline ACCOUNT FINANC & 0.875 & 0.537 & 1.629 & 0.794 & 0.046 & 0.907 & 10 & 2.03 & 0.412 & 0.00065 & 0.192 & 0.113 & 0.242 & 48 & 24 & 12 \\
\hline WORLD ECON & 0.872 & 0.797 & 1.094 & 1.244 & 0.135 & 1.427 & 36 & 3.92 & 0.491 & 0.00508 & 0.725 & 0.369 & 0.583 & 88 & 84 & 2 \\
\hline $\begin{array}{l}\text { J INT MONEY } \\
\text { FINANC }\end{array}$ & 0.858 & 0.742 & 1.156 & 1.434 & 0.305 & 1.671 & 59 & 11.64 & 0.194 & 0.00641 & 0.915 & 0.737 & 0.638 & 82 & 76 & 3 \\
\hline $\begin{array}{l}\text { INT REV ECON } \\
\text { FINANC }\end{array}$ & 0.855 & 0.366 & 2.336 & 1.104 & 0.231 & 1.291 & 11 & 1.99 & 0.394 & 0.00125 & - & - & - & 24 & -14 & 19 \\
\hline ABACUS & 0.85 & 0.85 & 1 & 1.01 & 0.105 & 1.188 & 11 & 2.62 & 0.446 & 0.00051 & 0.284 & 0.157 & 0.281 & 76 & 100 & -12 \\
\hline $\begin{array}{l}\text { AUST ACCOUNT } \\
\text { REV }\end{array}$ & 0.833 & 0.583 & 1.429 & 0.63 & 0.529 & 0.756 & 6 & 1.18 & 0.516 & 0.00028 & - & - & - & 42 & 40 & 1 \\
\hline $\begin{array}{l}\text { N AM J ECON } \\
\text { FINANC } \\
\end{array}$ & 0.825 & 0.55 & 1.5 & 1.133 & 0.143 & 1.373 & 8 & 1.95 & 0.323 & 0.0005 & - & - & - & 70 & 34 & 18 \\
\hline QUANT FINANC & 0.824 & 0.761 & 1.083 & 0.957 & 0.085 & 1.161 & 28 & 4.54 & 0.451 & 0.0046 & 0.633 & 0.348 & 0.661 & 74 & 86 & -6 \\
\hline $\begin{array}{l}\text { SIAM J FINANC } \\
\text { MATH }\end{array}$ & 0.795 & 0.795 & 1 & 0.795 & 0 & 1 & 8 & 2.21 & 0.407 & 0.00099 & 0.775 & 0.46 & 0.975 & 100 & 100 & 0 \\
\hline INT J FINANC ECON & 0.784 & 0.745 & 1.052 & 0.776 & 0.2 & 0.99 & 20 & 4.94 & 0.279 & 0.0009 & 0.413 & 0.298 & 0.532 & 94 & 90 & 2 \\
\hline $\begin{array}{l}\text { J FUTURES } \\
\text { MARKETS } \\
\end{array}$ & 0.782 & 0.564 & 1.387 & 0.855 & 0.152 & 1.093 & 37 & 6.61 & 0.206 & 0.00191 & 0.426 & 0.338 & 0.498 & 56 & 46 & 5 \\
\hline $\begin{array}{l}\text { J ACCOUNT PUBLIC } \\
\text { POL }\end{array}$ & 0.77 & 0.557 & 1.382 & 1.525 & 0.129 & 1.981 & 19 & 4.47 & 0.295 & 0.001 & - & - & - & 68 & 46 & 11 \\
\hline $\begin{array}{l}\text { EUR FINANC } \\
\text { MANAG }\end{array}$ & 0.738 & 0.631 & 1.17 & 1.431 & 0.111 & 1.939 & 19 & 5.54 & 0.254 & 0.00242 & 0.798 & 0.595 & 0.558 & 58 & 72 & -7 \\
\hline $\begin{array}{l}\text { GENEVA RISK INS } \\
\text { REV }\end{array}$ & 0.722 & 0.722 & 1 & 0.732 & 0.091 & 1.014 & 6 & 2.76 & 0.25 & 0.00032 & 0.441 & 0.331 & 0.602 & 78 & 100 & -11 \\
\hline NATL TAX J & 0.698 & 0.593 & 1.177 & 0.732 & 0.25 & 1.049 & 49 & 6.49 & 0.3 & 0.00211 & 0.577 & 0.404 & 0.788 & 76 & 70 & 3 \\
\hline $\begin{array}{l}\text { ANNU REV FINANC } \\
\text { ECON }\end{array}$ & 0.694 & 0.667 & 1.04 & 0.627 & 0.105 & 0.903 & 8 & 2.52 & 0.429 & 0.00099 & 1.111 & 0.634 & 1.772 & 90 & 92 & -1 \\
\hline EUR ACCOUNT REV & 0.654 & 0.558 & 1.172 & 1.465 & 0 & 2.24 & 15 & 3.63 & 0.441 & 0.00102 & 0.453 & 0.253 & 0.309 & 84 & 72 & 6 \\
\hline $\begin{array}{l}\text { FED RESERVE } \\
\text { BANK ST }\end{array}$ & 0.64 & 0.62 & 1.032 & 0.748 & 0.125 & 1.169 & 17 & 4.12 & 0.317 & 0.00185 & 0.786 & 0.537 & 1.051 & 86 & 94 & -4 \\
\hline $\begin{array}{l}\text { J REAL ESTATE } \\
\text { FINANC }\end{array}$ & 0.621 & 0.526 & 1.181 & 1.203 & 0.11 & 1.937 & 34 & 7.67 & 0.247 & 0.00217 & 0.536 & 0.404 & 0.446 & 54 & 70 & -8 \\
\hline
\end{tabular}




\begin{tabular}{|c|c|c|c|c|c|c|c|c|c|c|c|c|c|c|c|c|}
\hline Journal & 2YIF & 2 YIF* $^{*}$ & IFI & 5YIF & Immediacy & 5YD2 & $\begin{array}{c}\text { h- } \\
\text { index } \\
\end{array}$ & СЗРО & $\begin{array}{c}\text { PI- } \\
\text { BETA }\end{array}$ & Eigenfactor & $\begin{array}{c}\text { Article } \\
\text { Influence } \\
\end{array}$ & CAI & ICQ & $\begin{array}{c}\text { H- } \\
\text { STAR } \\
\end{array}$ & $\begin{array}{c}\text { 2Y- } \\
\text { STAR } \\
\end{array}$ & ESC \\
\hline INT FINANC & 0.6 & 0.575 & 1.043 & 0.927 & 0.118 & 1.545 & 8 & 2.09 & 0.496 & 0.00064 & 0.447 & 0.225 & 0.482 & 92 & 92 & 0 \\
\hline $\begin{array}{l}\text { INT J HEALTH } \\
\text { CARE FI }\end{array}$ & 0.576 & 0.545 & 1.057 & 1.27 & 0 & 2.205 & 7 & 1.97 & 0.416 & 0.00073 & - & - & - & 92 & 90 & 1 \\
\hline $\begin{array}{l}\text { PAC-BASIN } \\
\text { FINANC J }\end{array}$ & 0.571 & 0.333 & 1.715 & 1.162 & 0.068 & 2.035 & 7 & 1.46 & 0.514 & 0.00079 & - & - & - & 66 & 18 & 24 \\
\hline ACCOUNT BUS RES & 0.533 & 0.356 & 1.497 & 0.792 & 0.045 & 1.486 & 11 & 2.3 & 0.482 & 0.00042 & 0.227 & 0.118 & 0.287 & 44 & 34 & 5 \\
\hline $\begin{array}{l}\text { J PORTFOLIO } \\
\text { MANAGE }\end{array}$ & 0.525 & 0.232 & 2.263 & 0.562 & 0.093 & 1.07 & 35 & 3.91 & 0.431 & 0.00156 & 0.346 & 0.197 & 0.616 & 72 & -10 & 41 \\
\hline J COMPUT FINANC & 0.438 & 0.438 & 1 & 1.125 & 0 & 2.568 & 5 & 1.14 & 0.578 & 0.00095 & - & - & - & 100 & 100 & 0 \\
\hline $\begin{array}{l}\text { J PENSION ECON } \\
\text { FINAN }\end{array}$ & 0.418 & 0.273 & 1.531 & 0.563 & 0.043 & 1.347 & 7 & 0.85 & 0.703 & 0.00055 & - & - & - & 48 & 32 & 8 \\
\hline $\begin{array}{l}\text { ASIA-PAC J } \\
\text { FINANC ST } \\
\end{array}$ & 0.417 & 0.2 & 2.085 & 0.351 & 0.1 & 0.842 & 5 & 1.07 & 0.506 & 0.00013 & 0.049 & 0.024 & 0.14 & -6 & -4 & -1 \\
\hline J DERIV & 0.406 & 0.375 & 1.083 & 0.758 & 0.053 & 1.867 & 9 & 2.3 & 0.435 & 0.00084 & 0.528 & 0.298 & 0.697 & 96 & 86 & 5 \\
\hline $\begin{array}{l}\text { GENEVA PAP R I- } \\
\text { ISS P }\end{array}$ & 0.382 & 0.235 & 1.626 & 0.531 & 0.029 & 1.39 & 13 & 2.23 & 0.403 & 0.00054 & 0.161 & 0.096 & 0.303 & 26 & 24 & 1 \\
\hline FINANC UVER & 0.34 & 0.151 & 2.252 & 0.414 & 0.2 & 1.218 & 7 & 1.21 & 0.553 & 0.00027 & 0.116 & 0.052 & 0.28 & 46 & -10 & 28 \\
\hline $\begin{array}{l}\text { J INT FIN MANAG } \\
\text { ACC }\end{array}$ & 0.333 & 0.333 & 1 & 0.579 & 0 & 1.739 & 3 & 0.87 & 0.55 & 0.00013 & - & - & - & 96 & 100 & -2 \\
\hline J BEHAV FINANC & 0.3 & 0.2 & 1.5 & 0.646 & 0.037 & 2.153 & 5 & 0.98 & 0.587 & 0.00042 & - & - & - & 70 & 24 & 23 \\
\hline FISC STUD & 0.295 & 0.227 & 1.3 & 0.616 & 0.091 & 2.088 & 17 & 4.75 & 0.271 & 0.00083 & 0.48 & 0.35 & 0.779 & 94 & 54 & 20 \\
\hline FINANC RES LETT & 0.291 & 0.255 & 1.141 & 0.472 & 0.04 & 1.622 & 5 & 1.14 & 0.529 & 0.00066 & - & - & - & 92 & 76 & 8 \\
\hline $\begin{array}{l}\text { IKTISAT ISLET } \\
\text { FINANS }\end{array}$ & 0.278 & 0.01 & 27.8 & 0.416 & 0.235 & 1.496 & 4 & 0.49 & 0.679 & 0.00007 & - & - & - & -64 & -92 & 14 \\
\hline EUR J FINANC & 0.262 & 0.238 & 1.101 & 0.743 & 0.085 & 2.836 & 7 & 1.31 & 0.551 & 0.00121 & - & - & - & 78 & 82 & -2 \\
\hline FORBES & 0.251 & 0.251 & 1 & 0.123 & 0.131 & 0.49 & 4 & 0.02 & 0.982 & 0.0025 & 0.075 & 0.001 & 0.61 & 100 & 100 & 0 \\
\hline FINANZARCHIV & 0.229 & 0.171 & 1.339 & 0.312 & 0.056 & 1.362 & 9 & 1.64 & 0.537 & 0.00038 & 0.2 & 0.093 & 0.641 & 76 & 50 & 13 \\
\hline $\begin{array}{l}\text { ASIA-PAC J } \\
\text { ACCOUNT E }\end{array}$ & 0.206 & 0.118 & 1.746 & 0.25 & 0.136 & 1.214 & 4 & 0.51 & 0.765 & 0.00011 & - & - & - & 38 & 16 & 11 \\
\hline
\end{tabular}




\begin{tabular}{|c|c|c|c|c|c|c|c|c|c|c|c|c|c|c|c|c|}
\hline Journal & 2YIF & 2YIF* & IFI & 5YIF & Immediacy & 5YD2 & $\begin{array}{c}\text { h- } \\
\text { index }\end{array}$ & СЗРО & $\begin{array}{c}\text { PI- } \\
\text { BETA }\end{array}$ & Eigenfactor & $\begin{array}{c}\text { Article } \\
\text { Influence }\end{array}$ & CAI & ICQ & $\begin{array}{c}\text { H- } \\
\text { STAR }\end{array}$ & $\begin{array}{l}\text { 2Y- } \\
\text { STAR }\end{array}$ & ESC \\
\hline J OPER RISK & 0.182 & 0.182 & 1 & 0.427 & 0 & 2.346 & 11 & 3.2 & 0.466 & 0.00032 & - & - & - & 100 & 100 & 0 \\
\hline INVEST ANAL J & 0.176 & 0.059 & 2.983 & 0.313 & 0.182 & 1.778 & 3 & 0.69 & 0.662 & 0.00003 & 0.034 & 0.011 & 0.109 & -14 & -32 & 9 \\
\hline REV DERIV RES & 0.16 & 0.16 & 1 & 0.326 & 0 & 2.038 & 4 & 0.96 & 0.563 & 0.00021 & - & - & - & 100 & 100 & 0 \\
\hline J RISK & 0.152 & 0.152 & 1 & 0.507 & 0 & 3.336 & 5 & 0.96 & 0.632 & 0.00037 & - & - & - & 100 & 100 & 0 \\
\hline INT INSOLV REV & 0.15 & 0.1 & 1.5 & 0.258 & 0 & 1.72 & 2 & 0.36 & 0.709 & 0.00006 & - & - & - & 8 & 34 & -13 \\
\hline $\begin{array}{l}\text { REV ESP FINANC } \\
\text { CONTA }\end{array}$ & 0.106 & 0.043 & 2.465 & 0.167 & 0.048 & 1.575 & 2 & 0.15 & 0.876 & 0.00004 & - & - & - & -8 & -20 & 6 \\
\hline J CREDIT RISK & 0.091 & 0.091 & 1 & 0.389 & 0 & 4.275 & 4 & 0.68 & 0.633 & 0.0003 & - & - & - & 100 & 100 & 0 \\
\hline $\begin{array}{l}\text { J RISK MODEL } \\
\text { VALIDAT }\end{array}$ & 0.031 & 0.031 & 1 & 0.146 & 0 & 4.71 & 3 & 0.6 & 0.67 & 0.0001 & - & - & - & 100 & 100 & 0 \\
\hline JASSA & 0 & 0 & - & 0.036 & 0 & - & 2 & 0.07 & 0.95 & 0.00001 & - & - & - & - & - & - \\
\hline Mean & 1.006 & 0.806 & 1.679 & 1.424 & 0.171 & 1.577 & 29 & 7.406 & 0.396 & 0.00454 & 1.363 & 1.025 & 0.719 & 71 & 57 & 7 \\
\hline Low & 0 & 0 & 1 & 0.036 & 0 & 0.49 & 2 & 0.02 & 0.082 & 0.00001 & 0.034 & 0.001 & 0.109 & -64 & -92 & -13 \\
\hline High & 4.333 & 3.984 & 27.8 & 6.185 & 0.867 & 4.71 & 204 & 72.57 & 0.982 & 0.06476 & 8.824 & 6.46 & 1.772 & 100 & 100 & 46 \\
\hline
\end{tabular}

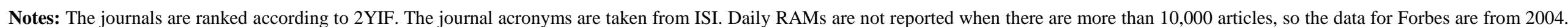
Data for all other journals are from the year of their inclusion in ISI. The data were downloaded from ISI on 14 May 2014. 
Table 2

Correlations of 16 RAM for 58 Leading Finance Journals

\begin{tabular}{|c|c|c|c|c|c|c|c|c|c|c|c|c|c|c|c|c|}
\hline Journal & 2 YIF & 2YIF* & IFI & $5 Y I F$ & Immediacy & 5YD2 & h-index & СЗРО & PI-BETA & Eigenfactor & $\begin{array}{c}\text { Article } \\
\text { Influence }\end{array}$ & CAI & ICQ & H-STAR & 2Y-STAR & ESC \\
\hline 2YIF & 1 & & & & & & & & & & & & & & & \\
\hline 2YIF* & 0.974 & 1 & & & & & & & & & & & & & & \\
\hline IFI & -0.217 & -0.383 & 1 & & & & & & & & & & & & & \\
\hline 5YIF & 0.936 & 0.917 & -0.244 & 1 & & & & & & & & & & & & \\
\hline Immediacy & 0.615 & 0.583 & -0.062 & 0.685 & 1 & & & & & & & & & & & \\
\hline 5YD2 & -0.054 & -0.029 & -0.099 & 0.222 & 0.069 & 1 & & & & & & & & & & \\
\hline h-index & 0.801 & 0.795 & -0.234 & 0.873 & 0.769 & 0.173 & 1 & & & & & & & & & \\
\hline CЗPO & 0.774 & 0.772 & -0.245 & 0.822 & 0.597 & 0.165 & 0.852 & 1 & & & & & & & & \\
\hline PI-BETA & -0.458 & -0.45 & 0.224 & -0.464 & -0.187 & -0.205 & -0.455 & -0.585 & 1 & & & & & & & \\
\hline Eigenfactor & 0.71 & 0.719 & -0.179 & 0.816 & 0.698 & 0.158 & 0.844 & 0.775 & -0.3 & 1 & & & & & & \\
\hline $\begin{array}{l}\text { Article } \\
\text { Influence }\end{array}$ & 0.846 & 0.876 & -0.3 & 0.896 & 0.653 & 0.12 & 0.828 & 0.762 & -0.361 & 0.901 & 1 & & & & & \\
\hline CAI & 0.835 & 0.862 & -0.291 & 0.893 & 0.629 & 0.134 & 0.835 & 0.845 & -0.446 & 0.927 & 0.979 & 1 & & & & \\
\hline ICQ & 0.452 & 0.548 & -0.524 & 0.422 & 0.264 & -0.083 & 0.424 & 0.42 & -0.296 & 0.472 & 0.674 & 0.645 & 1 & & & \\
\hline H-STAR & 0.326 & 0.427 & -0.715 & 0.328 & 0.161 & 0.025 & 0.335 & 0.327 & -0.275 & 0.247 & 0.373 & 0.366 & 0.633 & 1 & & \\
\hline 2Y-STAR & 0.246 & 0.422 & -0.946 & 0.259 & 0.052 & 0.064 & 0.231 & 0.253 & -0.207 & 0.202 & 0.342 & 0.329 & 0.584 & 0.776 & 1 & \\
\hline ESC & -0.054 & -0.226 & 0.750 & -0.072 & 0.081 & -0.074 & -0.021 & -0.065 & 0.043 & -0.065 & -0.155 & -0.142 & -0.27 & -0.198 & -0.772 & 1 \\
\hline
\end{tabular}


Table 3

Correlations of 13 RAM for 88 Leading Finance Journals

\begin{tabular}{|c|c|c|c|c|c|c|c|c|c|c|c|c|c|}
\hline Journal & 2YIF & 2YIF* & IFI & 5YIF & Immediacy & 5YD2 & h-index & CЗPO & PI-BETA & Eigenfactor & H-STAR & 2Y-STAR & ESC \\
\hline 2YIF & 1 & & & & & & & & & & & & \\
\hline 2YIF* & 0.971 & 1 & & & & & & & & & & & \\
\hline IFI & -0.119 & -0.168 & 1 & & & & & & & & & & \\
\hline 5YIF & 0.905 & 0.885 & -0.125 & 1 & & & & & & & & & \\
\hline Immediacy & 0.603 & 0.546 & 0.049 & 0.642 & 1 & & & & & & & & \\
\hline 5YD2 & -0.284 & -0.24 & -0.045 & 0.003 & -0.183 & 1 & & & & & & & \\
\hline h-index & 0.804 & 0.809 & -0.106 & 0.8 & 0.632 & -0.154 & 1 & & & & & & \\
\hline CЗPO & 0.779 & 0.788 & -0.102 & 0.765 & 0.509 & -0.127 & 0.874 & 1 & & & & & \\
\hline PI-BETA & -0.585 & -0.563 & 0.192 & -0.525 & -0.291 & 0.261 & -0.543 & -0.612 & 1 & & & & \\
\hline Eigenfactor & 0.7 & 0.72 & -0.07 & 0.755 & 0.575 & -0.055 & 0.842 & 0.786 & -0.345 & 1 & & & \\
\hline H-STAR & 0.241 & 0.352 & -0.583 & 0.228 & -0.037 & 0.125 & 0.279 & 0.272 & -0.323 & 0.207 & 1 & & \\
\hline 2Y-STAR & 0.169 & 0.348 & -0.533 & 0.192 & -0.099 & 0.206 & 0.205 & 0.221 & -0.205 & 0.183 & 0.842 & 1 & \\
\hline ESC & 0.017 & -0.159 & 0.184 & -0.043 & 0.13 & -0.207 & 0.003 & -0.034 & -0.064 & -0.053 & -0.183 & -0.684 & 1 \\
\hline
\end{tabular}


Table 4

14 RAM and Harmonic Mean (HM) of the Ranks for 58 Leading Finance Journals

\begin{tabular}{|c|c|c|c|c|c|c|c|c|c|c|c|c|c|c|c|c|}
\hline Journal & HM & 2YIF & 2 YIF* $^{*}$ & IFI & 5YIF & $\begin{array}{c}\text { Imme- } \\
\text { diacy }\end{array}$ & 5YD2 & $\begin{array}{c}\mathrm{h}- \\
\text { index }\end{array}$ & СЗРО & $\begin{array}{c}\text { PI- } \\
\text { BETA }\end{array}$ & $\begin{array}{l}\text { Eigen- } \\
\text { factor }\end{array}$ & AI & CAI & ICQ & ESC & $\begin{array}{r}\text { 2YIF- } \\
\text { HM }\end{array}$ \\
\hline J FINANC & 1 & 1 & 1 & 15 & 1 & 1 & 20 & 1 & 4 & 35 & 3 & 1 & 3 & 4 & 19 & 0 \\
\hline J FINANC ECON & 2 & 3 & 3 & 24 & 3 & 2 & 17 & 2 & 1 & 1 & 2 & 3 & 2 & 6 & 31 & 1 \\
\hline REV FINANC STUD & 3 & 4 & 4 & 26 & 2 & 4 & 11 & 4 & 3 & 4 & 1 & 2 & 1 & 5 & 35 & 1 \\
\hline J ACCOUNT ECON & 4 & 2 & 2 & 36 & 4 & 10 & 48 & 5 & 2 & 2 & 9 & 8 & 6 & 31 & 35 & -2 \\
\hline ABACUS & 5 & 36 & 25 & 1 & 37 & 42 & 35 & 43 & 46 & 46 & 52 & 50 & 50 & 53 & 1 & 31 \\
\hline J MONETARY ECON & 6 & 12 & 11 & 19 & 10 & 26 & 16 & 3 & 5 & 10 & 4 & 5 & 4 & 3 & 38 & 6 \\
\hline IMF STAFF PAPERS & 7 & 7 & 5 & 1 & 31 & 55 & 57 & 29 & 21 & 8 & 28 & 19 & 16 & 13 & 12 & 0 \\
\hline GENEVA RISK INS REV & 8 & 42 & 33 & 1 & 48 & 46 & 49 & 55 & 45 & 26 & 55 & 44 & 41 & 33 & 2 & 34 \\
\hline IMF ECON REV & 9 & 5 & 6 & 28 & 9 & 55 & 50 & 43 & 40 & 41 & 27 & 4 & 5 & 2 & 7 & -4 \\
\hline ANNU REV FINANC ECON & 10 & 44 & 34 & 10 & 50 & 42 & 55 & 51 & 47 & 42 & 43 & 21 & 28 & 1 & 7 & 34 \\
\hline WORLD BANK ECON REV & 11 & 18 & 14 & 6 & 8 & 30 & 3 & 14 & 7 & 22 & 17 & 10 & 10 & 21 & 12 & 7 \\
\hline SIAM J FINANC MATH & 12 & 38 & 28 & 1 & 42 & 55 & 52 & 51 & 51 & 39 & 43 & 32 & 31 & 17 & 12 & 26 \\
\hline J ACCOUNT RES & 13 & 9 & 8 & 33 & 5 & 12 & 15 & 6 & 8 & 14 & 10 & 9 & 9 & 26 & 41 & -4 \\
\hline FORBES & 14 & 56 & 51 & 1 & 58 & 32 & 58 & 57 & 58 & 58 & 26 & 56 & 58 & 31 & 12 & 42 \\
\hline J FINANC QUANT ANAL & 15 & 13 & 10 & 8 & 13 & 17 & 31 & 8 & 12 & 16 & 7 & 7 & 8 & 7 & 22 & -2 \\
\hline EUR ACCOUNT REV & 16 & 45 & 43 & 32 & 25 & 55 & 1 & 40 & 41 & 45 & 42 & 42 & 45 & 49 & 35 & 29 \\
\hline ACCOUNT REV & 17 & 6 & 9 & 39 & 6 & 3 & 25 & 7 & 29 & 56 & 8 & 18 & 27 & 45 & 43 & -11 \\
\hline J FINANC INTERMED & 18 & 8 & 7 & 8 & 11 & 41 & 43 & 19 & 13 & 15 & 12 & 6 & 7 & 11 & 12 & -10 \\
\hline ACCOUNT ORG SOC & 19 & 10 & 12 & 37 & 7 & 34 & 9 & 12 & 9 & 3 & 20 & 25 & 19 & 48 & 41 & -9 \\
\hline J RISK UNCERTAINTY & 20 & 11 & 15 & 42 & 14 & 25 & 40 & 15 & 6 & 5 & 21 & 16 & 13 & 19 & 48 & -9 \\
\hline
\end{tabular}




\begin{tabular}{|c|c|c|c|c|c|c|c|c|c|c|c|c|c|c|c|c|}
\hline Journal & HM & 2YIF & 2 YIF* $^{*}$ & IFI & 5YIF & $\begin{array}{c}\text { Imme- } \\
\text { diacy }\end{array}$ & 5YD2 & $\begin{array}{c}\text { h- } \\
\text { index }\end{array}$ & СЗРО & $\begin{array}{c}\text { PI- } \\
\text { BETA }\end{array}$ & $\begin{array}{l}\text { Eigen- } \\
\text { factor }\end{array}$ & AI & CAI & ICQ & ESC & $\begin{array}{c}\text { 2YIF- } \\
\text { HM }\end{array}$ \\
\hline MATH FINANC & 21 & 29 & 21 & 15 & 26 & 7 & 19 & 18 & 10 & 6 & 18 & 17 & 15 & 15 & 22 & 8 \\
\hline J MONEY CREDIT BANK & 22 & 23 & 19 & 23 & 18 & 8 & 14 & 10 & 14 & 29 & 6 & 15 & 17 & 16 & 29 & 1 \\
\hline FINANC STOCH & 23 & 21 & 17 & 19 & 19 & 11 & 30 & 29 & 16 & 11 & 19 & 12 & 12 & 10 & 7 & -2 \\
\hline J IND ECON & 24 & 22 & 18 & 18 & 23 & 22 & 32 & 11 & 11 & 12 & 13 & 11 & 11 & 8 & 38 & -2 \\
\hline J BANK FINANC & 25 & 19 & 26 & 45 & 17 & 18 & 29 & 9 & 17 & 6 & 5 & 28 & 25 & 43 & 45 & -6 \\
\hline J REAL ESTATE FINANC & 26 & 47 & 45 & 35 & 34 & 40 & 5 & 26 & 26 & 24 & 33 & 37 & 32 & 46 & 3 & 21 \\
\hline EUR FINANC MANAG & 27 & 41 & 36 & 31 & 28 & 39 & 4 & 37 & 30 & 27 & 29 & 27 & 29 & 37 & 4 & 14 \\
\hline FISC STUD & 28 & 55 & 54 & 38 & 51 & 46 & 2 & 38 & 33 & 28 & 48 & 41 & 37 & 22 & 51 & 27 \\
\hline J INT MONEY FINANC & 29 & 35 & 31 & 29 & 27 & 9 & 10 & 13 & 15 & 13 & 11 & 26 & 24 & 29 & 26 & 6 \\
\hline J FINANC ECONOMET & 30 & 30 & 23 & 21 & 21 & 46 & 12 & 41 & 35 & 36 & 25 & 13 & 18 & 12 & 7 & 0 \\
\hline J FINANC MARK & 31 & 24 & 20 & 22 & 24 & 15 & 26 & 34 & 18 & 19 & 24 & 14 & 14 & 9 & 29 & -7 \\
\hline FED RESERVE BANK ST & 32 & 46 & 37 & 7 & 47 & 34 & 37 & 38 & 35 & 34 & 36 & 30 & 30 & 14 & 6 & 14 \\
\hline CONTEMP ACCOUNT RES & 33 & 14 & 13 & 25 & 12 & 23 & 26 & 27 & 22 & 31 & 22 & 22 & 23 & 39 & 19 & -19 \\
\hline J CORP FINANC & 34 & 25 & 35 & 47 & 16 & 27 & 8 & 20 & 19 & 21 & 15 & 24 & 22 & 35 & 53 & -9 \\
\hline QUANT FINANC & 35 & 37 & 29 & 13 & 39 & 49 & 38 & 31 & 34 & 47 & 16 & 35 & 38 & 25 & 5 & 2 \\
\hline REV ACCOUNT STUD & 36 & 16 & 16 & 26 & 15 & 16 & 22 & 32 & 24 & 33 & 31 & 20 & 20 & 28 & 26 & -20 \\
\hline FINANC MANAGE & 37 & 17 & 22 & 43 & 22 & 14 & 36 & 17 & 23 & 18 & 23 & 23 & 21 & 24 & 52 & -20 \\
\hline REAL ESTATE ECON & 38 & 26 & 24 & 30 & 32 & 36 & 33 & 28 & 20 & 9 & 37 & 31 & 26 & 34 & 12 & -12 \\
\hline FINANC ANAL J & 39 & 31 & 39 & 46 & 38 & 5 & 51 & 32 & 42 & 55 & 30 & 29 & 39 & 18 & 55 & -8 \\
\hline J DERIV & 40 & 52 & 48 & 13 & 46 & 51 & 6 & 49 & 48 & 44 & 47 & 38 & 43 & 23 & 31 & 12 \\
\hline
\end{tabular}




\begin{tabular}{|c|c|c|c|c|c|c|c|c|c|c|c|c|c|c|c|c|}
\hline Journal & HM & 2YIF & 2YIF* & IFI & 5YIF & $\begin{array}{c}\text { Imme- } \\
\text { diacy }\end{array}$ & 5YD2 & $\begin{array}{c}\mathbf{h}- \\
\text { index }\end{array}$ & СЗРО & $\begin{array}{c}\text { PI- } \\
\text { BETA }\end{array}$ & $\begin{array}{l}\text { Eigen- } \\
\text { factor }\end{array}$ & AI & CAI & ICQ & ESC & $\begin{array}{r}2 \text { YIF } \\
\text { HM }\end{array}$ \\
\hline WORLD ECON & 41 & 34 & 27 & 17 & 33 & 31 & 20 & 23 & 38 & 50 & 14 & 33 & 35 & 36 & 22 & -7 \\
\hline J REAL ESTATE RES & 42 & 32 & 46 & 52 & 35 & 6 & 39 & 47 & 43 & 22 & 45 & 39 & 34 & 42 & 49 & -10 \\
\hline NATL TAX J & 43 & 43 & 40 & 33 & 48 & 13 & 47 & 16 & 28 & 32 & 34 & 36 & 32 & 20 & 26 & 0 \\
\hline INT FINANC & 44 & 48 & 41 & 11 & 40 & 36 & 13 & 51 & 52 & 51 & 50 & 43 & 47 & 41 & 12 & 4 \\
\hline INT J FINANC ECON & 45 & 39 & 30 & 12 & 45 & 19 & 53 & 36 & 31 & 30 & 45 & 46 & 43 & 38 & 22 & -6 \\
\hline AUDITING-J PRACT TH & 46 & 27 & 38 & 50 & 29 & 19 & 24 & 23 & 25 & 25 & 41 & 40 & 36 & 47 & 50 & -19 \\
\hline J FUTURES MARKETS & 47 & 40 & 42 & 41 & 41 & 29 & 44 & 22 & 27 & 16 & 35 & 45 & 40 & 40 & 31 & -7 \\
\hline J RISK INSUR & 48 & 20 & 32 & 51 & 30 & 38 & 42 & 20 & 37 & 49 & 32 & 34 & 42 & 43 & 45 & -28 \\
\hline INVEST ANAL J & 49 & 58 & 58 & 56 & 56 & 24 & 7 & 58 & 57 & 57 & 58 & 58 & 57 & 58 & 40 & 9 \\
\hline CORP GOV-OXFORD & 50 & 15 & 47 & 58 & 20 & 28 & 41 & 43 & 44 & 37 & 38 & 47 & 48 & 56 & 56 & -35 \\
\hline ASIA-PAC J FINANC ST & 51 & 51 & 55 & 53 & 55 & 44 & 56 & 56 & 56 & 52 & 57 & 57 & 56 & 57 & 7 & 0 \\
\hline J BUS FINAN ACCOUNT & 52 & 28 & 50 & 57 & 36 & 33 & 46 & 35 & 32 & 20 & 40 & 49 & 46 & 51 & 58 & -24 \\
\hline GENEVA PAP R I-ISS P & 53 & 53 & 52 & 48 & 53 & 54 & 23 & 41 & 50 & 38 & 51 & 54 & 53 & 50 & 19 & 0 \\
\hline ACCOUNT BUS RES & 54 & 49 & 49 & 44 & 44 & 53 & 17 & 43 & 48 & 48 & 53 & 51 & 51 & 52 & 31 & -5 \\
\hline J PORTFOLIO MANAGE & 55 & 50 & 53 & 55 & 52 & 45 & 45 & 25 & 39 & 43 & 39 & 48 & 49 & 30 & 57 & -5 \\
\hline FINANZARCHIV & 56 & 57 & 56 & 40 & 57 & 50 & 28 & 49 & 54 & 53 & 54 & 52 & 54 & 27 & 45 & 1 \\
\hline FINANC UVER & 57 & 54 & 57 & 54 & 54 & 19 & 34 & 54 & 55 & 54 & 56 & 55 & 55 & 54 & 54 & -3 \\
\hline ACCOUNT FINANC & 58 & 33 & 44 & 49 & 43 & 52 & 54 & 47 & 53 & 40 & 49 & 53 & 52 & 55 & 44 & -25 \\
\hline
\end{tabular}

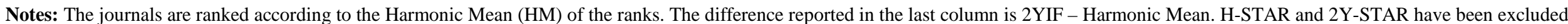
as there were 9 and 12 journals, respectively, that had the equal highest rank. 
Table 5

10 RAM and Harmonic Mean (HM) of the Ranks for 88 Leading Finance Journals

\begin{tabular}{|c|c|c|c|c|c|c|c|c|c|c|c|c|}
\hline Journal & HM & 2YIF & 2YIF* & 5YIF & Immediacy & 5YD2 & h-index & СЗРО & PI-BETA & Eigenfactor & ESC & 2YIF-HM \\
\hline J FINANC & 1 & 1 & 1 & 1 & 1 & 42 & 1 & 4 & 39 & 3 & 30 & 0 \\
\hline J FINANC ECON & 2 & 3 & 3 & 3 & 2 & 38 & 2 & 1 & 1 & 2 & 45 & 1 \\
\hline REV FINANC STUD & 3 & 4 & 4 & 2 & 6 & 29 & 4 & 3 & 4 & 1 & 50 & 1 \\
\hline J ACCOUNT ECON & 4 & 2 & 2 & 5 & 16 & 77 & 5 & 2 & 2 & 9 & 50 & -2 \\
\hline ACCOUNT AUDIT ACCOUN & 5 & 40 & 41 & 4 & 8 & 2 & 61 & 67 & 70 & 44 & 4 & 35 \\
\hline J MONETARY ECON & 6 & 12 & 11 & 12 & 35 & 36 & 3 & 5 & 10 & 4 & 54 & 6 \\
\hline J RISK MODEL VALIDAT & 7 & 88 & 87 & 87 & 76 & 1 & 84 & 83 & 82 & 84 & 16 & 81 \\
\hline INT INSOLV REV & 8 & 85 & 83 & 84 & 76 & 23 & 87 & 86 & 85 & 86 & 1 & 77 \\
\hline ACCOUNT REV & 9 & 6 & 9 & 7 & 4 & 48 & 7 & 29 & 76 & 8 & 62 & -3 \\
\hline J ACCOUNT RES & 10 & 9 & 8 & 6 & 18 & 35 & 6 & 8 & 14 & 10 & 60 & -1 \\
\hline ACCOUNT ORG SOC & 11 & 10 & 12 & 8 & 46 & 26 & 12 & 9 & 3 & 22 & 60 & -1 \\
\hline J RISK UNCERTAINTY & 12 & 11 & 16 & 18 & 34 & 68 & 15 & 6 & 5 & 23 & 70 & -1 \\
\hline J FINANC QUANT ANAL & 13 & 13 & 10 & 16 & 25 & 57 & 8 & 12 & 16 & 7 & 35 & 0 \\
\hline J BANK FINANC & 14 & 23 & 30 & 21 & 26 & 55 & 9 & 17 & 6 & 5 & 67 & 9 \\
\hline J FINANC INTERMED & 15 & 8 & 7 & 13 & 55 & 71 & 19 & 13 & 15 & 12 & 16 & -7 \\
\hline WORLD BANK ECON REV & 16 & 21 & 15 & 9 & 39 & 12 & 14 & 7 & 22 & 19 & 16 & 5 \\
\hline IMF STAFF PAPERS & 17 & 7 & 5 & 40 & 76 & 87 & 29 & 21 & 8 & 30 & 16 & -10 \\
\hline IMF ECON REV & 18 & 5 & 6 & 10 & 76 & 79 & 48 & 44 & 51 & 29 & 11 & -13 \\
\hline ABACUS & 19 & 46 & 29 & 52 & 56 & 63 & 48 & 54 & 57 & 68 & 2 & 27 \\
\hline MATH FINANC & 20 & 35 & 23 & 35 & 10 & 40 & 18 & 10 & 6 & 20 & 35 & 15 \\
\hline
\end{tabular}




\begin{tabular}{|c|c|c|c|c|c|c|c|c|c|c|c|c|}
\hline Journal & $\mathbf{H M}$ & 2YIF & 2YIF* & 5YIF & Immediacy & 5YD2 & h-index & CЗPO & PI-BETA & Eigenfactor & ESC & 2YIF-HM \\
\hline J MONEY CREDIT BANK & 21 & 29 & 21 & 23 & 14 & 34 & 10 & 14 & 29 & 6 & 43 & 8 \\
\hline J FINANC SERV RES & 22 & 27 & 38 & 22 & 3 & 41 & 34 & 30 & 34 & 54 & 80 & 5 \\
\hline FINANC STOCH & 23 & 25 & 18 & 26 & 17 & 56 & 29 & 16 & 11 & 21 & 11 & 2 \\
\hline J IND ECON & 24 & 26 & 19 & 31 & 31 & 59 & 11 & 11 & 12 & 13 & 54 & 2 \\
\hline REV FINANC & 25 & 16 & 13 & 14 & 12 & 25 & 40 & 37 & 41 & 17 & 16 & -9 \\
\hline J INT MONEY FINANC & 26 & 44 & 37 & 36 & 15 & 27 & 13 & 15 & 13 & 11 & 40 & 18 \\
\hline GENEVA RISK INS REV & 27 & 55 & 40 & 64 & 60 & 78 & 72 & 52 & 26 & 75 & 3 & 28 \\
\hline J CREDIT RISK & 28 & 87 & 84 & 79 & 76 & 3 & 79 & 82 & 80 & 77 & 16 & 59 \\
\hline J REAL ESTATE FINANC & 29 & 60 & 57 & 45 & 54 & 17 & 26 & 26 & 24 & 35 & 5 & 31 \\
\hline CONTEMP ACCOUNT RES & 30 & 14 & 14 & 15 & 32 & 49 & 27 & 22 & 31 & 24 & 30 & -16 \\
\hline EUR FINANC MANAG & 31 & 54 & 44 & 37 & 53 & 16 & 38 & 31 & 27 & 31 & 6 & 23 \\
\hline EUR J FINANC & 32 & 77 & 71 & 63 & 64 & 5 & 67 & 70 & 72 & 46 & 9 & 45 \\
\hline J RISK & 33 & 84 & 80 & 74 & 76 & 4 & 74 & 77 & 79 & 73 & 16 & 51 \\
\hline REAL ESTATE ECON & 34 & 32 & 26 & 41 & 49 & 60 & 28 & 20 & 9 & 40 & 16 & -2 \\
\hline J CORP FINANC & 35 & 31 & 43 & 20 & 36 & 24 & 20 & 19 & 21 & 15 & 81 & -4 \\
\hline FINANC MANAGE & 36 & 20 & 24 & 29 & 20 & 64 & 17 & 23 & 18 & 25 & 78 & -16 \\
\hline REV ACCOUNT STUD & 37 & 19 & 17 & 19 & 24 & 45 & 32 & 24 & 35 & 33 & 40 & -18 \\
\hline ACCOUNT HORIZ & 38 & 22 & 20 & 17 & 13 & 28 & 48 & 53 & 52 & 47 & 35 & -16 \\
\hline QUANT FINANC & 39 & 49 & 35 & 54 & 64 & 66 & 31 & 35 & 58 & 18 & 7 & 10 \\
\hline J FINANC MARK & 40 & 30 & 22 & 33 & 23 & 49 & 35 & 18 & 19 & 26 & 43 & -10 \\
\hline
\end{tabular}




\begin{tabular}{|c|c|c|c|c|c|c|c|c|c|c|c|c|}
\hline Journal & $\mathbf{H M}$ & 2YIF & 2 YIF* $^{*}$ & 5YIF & Immediacy & 5YD2 & h-index & СЗРО & PI-BETA & Eigenfactor & ESC & 2YIF-HM \\
\hline MANAGE ACCOUNT RES & 41 & 18 & 27 & 11 & 49 & 19 & 48 & 38 & 36 & 49 & 75 & -23 \\
\hline AUST ACCOUNT REV & 42 & 47 & 49 & 67 & 5 & 86 & 72 & 72 & 66 & 78 & 30 & 5 \\
\hline J COMPUT FINANC & 43 & 66 & 60 & 48 & 76 & 6 & 74 & 73 & 77 & 55 & 16 & 23 \\
\hline J FINANC ECONOMET & 44 & 36 & 25 & 28 & 60 & 31 & 45 & 39 & 44 & 27 & 11 & -8 \\
\hline FINANC ANAL J & 45 & 37 & 47 & 53 & 7 & 80 & 32 & 46 & 75 & 32 & 85 & -8 \\
\hline J OPER RISK & 46 & 81 & 77 & 76 & 76 & 7 & 48 & 50 & 59 & 75 & 16 & 35 \\
\hline FED RESERVE BANK ST & 47 & 59 & 45 & 62 & 46 & 65 & 40 & 39 & 36 & 39 & 8 & 12 \\
\hline J EMPIR FINANC & 48 & 38 & 31 & 24 & 48 & 21 & 44 & 48 & 40 & 16 & 54 & -10 \\
\hline EUR ACCOUNT REV & 49 & 58 & 52 & 34 & 76 & 8 & 43 & 45 & 56 & 50 & 50 & 9 \\
\hline WORLD ECON & 50 & 43 & 33 & 44 & 42 & 42 & 23 & 42 & 62 & 14 & 35 & -7 \\
\hline J REAL ESTATE RES & 51 & 39 & 58 & 50 & 9 & 67 & 56 & 47 & 22 & 57 & 72 & -12 \\
\hline NATL TAX J & 52 & 56 & 48 & 64 & 19 & 76 & 16 & 28 & 33 & 36 & 40 & 4 \\
\hline AUDITING-J PRACT TH & 53 & 33 & 46 & 38 & 28 & 47 & 23 & 25 & 25 & 48 & 73 & -20 \\
\hline J FUTURES MARKETS & 54 & 52 & 51 & 56 & 38 & 72 & 22 & 27 & 16 & 38 & 45 & -2 \\
\hline J FINANC STABIL & 55 & 15 & 27 & 29 & 27 & 73 & 45 & 48 & 43 & 55 & 62 & -40 \\
\hline EMERG MARK REV & 56 & 28 & 59 & 25 & 11 & 51 & 61 & 60 & 42 & 74 & 78 & -28 \\
\hline INT J HEALTH CARE FI & 57 & 62 & 55 & 43 & 76 & 9 & 67 & 64 & 50 & 62 & 30 & 5 \\
\hline J ACCOUNT PUBLIC POL & 58 & 53 & 53 & 32 & 44 & 15 & 38 & 36 & 32 & 51 & 62 & -5 \\
\hline FISC STUD & 59 & 74 & 74 & 69 & 60 & 11 & 40 & 34 & 28 & 60 & 77 & 15 \\
\hline J INT FIN MANAG ACC & 60 & 72 & 65 & 70 & 76 & 22 & 84 & 79 & 71 & 81 & 9 & 12 \\
\hline
\end{tabular}




\begin{tabular}{|c|c|c|c|c|c|c|c|c|c|c|c|c|}
\hline Journal & HM & 2YIF & 2YIF* & 5YIF & Immediacy & 5YD2 & h-index & CЗPO & PI-BETA & Eigenfactor & ESC & 2YIF-HM \\
\hline J RISK INSUR & 61 & 24 & 39 & 39 & 52 & 70 & 20 & 41 & 61 & 34 & 67 & -37 \\
\hline CORP GOV-OXFORD & 62 & 17 & 61 & 27 & 37 & 69 & 48 & 51 & 45 & 41 & 86 & -45 \\
\hline ANNU REV FINANC ECON & 63 & 57 & 42 & 68 & 56 & 84 & 61 & 55 & 52 & 52 & 11 & -6 \\
\hline INT J FINANC ECON & 64 & 51 & 36 & 60 & 28 & 82 & 37 & 32 & 30 & 57 & 35 & -13 \\
\hline J BUS FINAN ACCOUNT & 65 & 34 & 67 & 51 & 45 & 75 & 36 & 33 & 20 & 43 & 88 & -31 \\
\hline REV DERIV RES & 66 & 83 & 79 & 81 & 76 & 13 & 79 & 77 & 74 & 80 & 16 & 17 \\
\hline INT FINANC & 67 & 61 & 50 & 55 & 49 & 33 & 61 & 61 & 63 & 65 & 16 & -6 \\
\hline SIAM J FINANC MATH & 68 & 50 & 34 & 57 & 76 & 81 & 61 & 59 & 48 & 52 & 16 & -18 \\
\hline J BEHAV FINANC & 69 & 73 & 75 & 66 & 74 & 10 & 74 & 76 & 78 & 70 & 81 & 4 \\
\hline INT J CENT BANK & 70 & 41 & 32 & 42 & 63 & 42 & 56 & 66 & 69 & 37 & 45 & -29 \\
\hline ASIA-PAC J FINANC ST & 71 & 68 & 75 & 80 & 58 & 85 & 74 & 75 & 64 & 81 & 11 & -3 \\
\hline INT REV ECON FINANC & 72 & 45 & 63 & 49 & 22 & 58 & 48 & 63 & 46 & 45 & 75 & -27 \\
\hline PAC-BASIN FINANC J & 73 & 63 & 65 & 46 & 66 & 14 & 67 & 69 & 65 & 61 & 83 & -10 \\
\hline J DERIV & 74 & 69 & 62 & 61 & 68 & 18 & 59 & 56 & 55 & 59 & 45 & -5 \\
\hline FORBES & 75 & 78 & 70 & 88 & 43 & 88 & 79 & 88 & 88 & 28 & 16 & 3 \\
\hline N AM J ECON FINANC & 76 & 48 & 54 & 47 & 39 & 52 & 61 & 65 & 38 & 69 & 74 & -28 \\
\hline J PORTFOLIO MANAGE & 77 & 65 & 73 & 72 & 59 & 74 & 25 & 43 & 54 & 42 & 87 & -12 \\
\hline GENEVA PAP R I-ISS P & 78 & 70 & 72 & 73 & 75 & 46 & 45 & 58 & 47 & 67 & 30 & -8 \\
\hline INVEST ANAL J & 79 & 82 & 85 & 82 & 33 & 20 & 84 & 81 & 81 & 88 & 59 & 3 \\
\hline ACCOUNT BUS RES & 80 & 64 & 64 & 59 & 71 & 38 & 48 & 56 & 60 & 70 & 45 & -16 \\
\hline
\end{tabular}




\begin{tabular}{|c|c|c|c|c|c|c|c|c|c|c|c|c|}
\hline Journal & HM & 2YIF & 2YIF* & 5YIF & Immediacy & 5YD2 & h-index & СЗРО & PI-BETA & Eigenfactor & ESC & 2YIF-HM \\
\hline IKTISAT ISLET FINANS & 81 & 76 & 88 & 77 & 20 & 37 & 79 & 85 & 83 & 85 & 70 & -5 \\
\hline ACCOUNT FINANC & 82 & 42 & 56 & 58 & 70 & 83 & 56 & 62 & 49 & 64 & 66 & -40 \\
\hline FINANC RES LETT & 83 & 75 & 69 & 75 & 73 & 30 & 74 & 73 & 67 & 63 & 57 & -8 \\
\hline FINANC UVER & 84 & 71 & 81 & 78 & 28 & 61 & 67 & 71 & 73 & 79 & 84 & -13 \\
\hline J PENSION ECON FINAN & 85 & 67 & 68 & 71 & 72 & 54 & 67 & 80 & 84 & 66 & 57 & -18 \\
\hline REV ESP FINANC CONTA & 86 & 86 & 86 & 86 & 69 & 32 & 87 & 87 & 87 & 87 & 50 & 0 \\
\hline FINANZARCHIV & 87 & 79 & 78 & 83 & 67 & 53 & 59 & 68 & 68 & 72 & 67 & -8 \\
\hline ASIA-PAC J ACCOUNT E & 88 & 80 & 82 & 85 & 41 & 62 & 79 & 84 & 86 & 83 & 62 & -8 \\
\hline
\end{tabular}

Notes: The journals are ranked according to the Harmonic Mean (HM) of the ranks. The difference reported in the last column is 2YIF - Harmonic Mean. IFI, H-STAR and 2Y-STAR have been excluded as there were 12, 9 and 12 journals, respectively, that had the equal highest rank. Article Influence, CAI and ICQ were not available for 30 journals. 
Table 6

Correlations of 14 RAM and Harmonic Mean (HM) of the Ranks for 58 Leading Finance Journals

\begin{tabular}{|c|c|c|c|c|c|c|c|c|c|c|c|c|c|c|c|}
\hline Journal & 2YIF & 2YIF* & IFI & 5YIF & $\begin{array}{c}\text { Imme- } \\
\text { diacy }\end{array}$ & 5YD2 & h-index & СЗРО & PI-BETA & $\begin{array}{l}\text { Eigen- } \\
\text { factor }\end{array}$ & AI & CAI & ICQ & ESC & HM \\
\hline 2YIF & 1 & & & & & & & & & & & & & & \\
\hline 2YIF* & 0.894 & 1 & & & & & & & & & & & & & \\
\hline IFI & 0.115 & 0.11 & 1 & & & & & & & & & & & & \\
\hline 5YIF & 0.798 & 0.902 & 0.114 & 1 & & & & & & & & & & & \\
\hline Immediacy & 0.441 & 0.469 & -0.103 & 0.49 & 1 & & & & & & & & & & \\
\hline 5YD2 & -0.048 & 0.004 & -0.034 & 0.314 & 0.13 & 1 & & & & & & & & & \\
\hline h-index & 0.641 & 0.679 & 0.028 & 0.769 & 0.598 & 0.265 & 1 & & & & & & & & \\
\hline СЗРО & 0.703 & 0.737 & 0.178 & 0.819 & 0.573 & 0.293 & 0.907 & 1 & & & & & & & \\
\hline PI-BETA & 0.586 & 0.579 & 0.108 & 0.591 & 0.373 & 0.137 & 0.65 & 0.839 & 1 & & & & & & \\
\hline Eigenfactor & 0.632 & 0.705 & 0.247 & 0.82 & 0.57 & 0.222 & 0.864 & 0.837 & 0.563 & 1 & & & & & \\
\hline AI & 0.746 & 0.794 & 0.384 & 0.848 & 0.451 & 0.204 & 0.719 & 0.821 & 0.599 & 0.839 & 1 & & & & \\
\hline CAI & 0.765 & 0.796 & 0.357 & 0.848 & 0.461 & 0.207 & 0.745 & 0.879 & 0.723 & 0.825 & 0.979 & 1 & & & \\
\hline ICQ & 0.405 & 0.387 & 0.573 & 0.373 & 0.218 & -0.028 & 0.385 & 0.506 & 0.373 & 0.557 & 0.776 & 0.742 & 1 & & \\
\hline ESC & -0.042 & -0.103 & 0.731 & -0.067 & -0.312 & -0.062 & -0.216 & -0.061 & -0.057 & -0.014 & 0.144 & 0.132 & 0.257 & 1 & \\
\hline HM & 0.568 & 0.552 & 0.626 & 0.611 & 0.212 & 0.093 & 0.421 & 0.548 & 0.427 & 0.583 & 0.713 & 0.709 & 0.587 & 0.376 & 1 \\
\hline
\end{tabular}

Note: The Harmonic Mean of the ranks is given as HM. 
Table 7

Correlations of 11 RAM and Harmonic Mean (HM) of the Ranks for 88 Leading Finance Journals

\begin{tabular}{|c|c|c|c|c|c|c|c|c|c|c|c|}
\hline Journal & 2YIF & 2 YIF* & 5YIF & Immediacy & 5YD2 & h-index & C3PO & PI-BETA & Eigenfactor & ESC & HM \\
\hline 2YIF & 1 & & & & & & & & & & \\
\hline $2 Y I F *$ & 0.916 & 1 & & & & & & & & & \\
\hline $5 Y I F$ & 0.918 & 0.872 & 1 & & & & & & & & \\
\hline Immediacy & 0.594 & 0.489 & 0.549 & 1 & & & & & & & \\
\hline 5YD2 & -0.311 & -0.239 & 0.032 & -0.228 & 1 & & & & & & \\
\hline h-index & 0.779 & 0.777 & 0.743 & 0.537 & -0.196 & 1 & & & & & \\
\hline C3PO & 0.799 & 0.822 & 0.772 & 0.515 & -0.162 & 0.955 & 1 & & & & \\
\hline PI-BETA & 0.709 & 0.702 & 0.663 & 0.434 & -0.213 & 0.794 & 0.899 & 1 & & & \\
\hline Eigenfactor & 0.781 & 0.827 & 0.785 & 0.492 & -0.138 & 0.876 & 0.846 & 0.675 & 1 & & \\
\hline ESC & -0.168 & 0.115 & -0.11 & -0.309 & 0.118 & -0.178 & -0.087 & -0.103 & -0.018 & 1 & \\
\hline HM & 0.612 & 0.690 & 0.673 & 0.377 & 0.14 & 0.581 & 0.648 & 0.528 & 0.625 & 0.327 & 1 \\
\hline
\end{tabular}

Note: The Harmonic Mean of the ranks is given as HM. 